\title{
Oblikospreminjevalni vzorci glagola v gorenjskem kroparskem govoru
}

\author{
Jožica Škofic
}

\begin{abstract}
IZVLEČEK: Paradigmatika glagolskih oblik, tj. njegovih oblikotvornih in oblikospreminjevalnih vzorcev, v gorenjskem kroparskem govoru (SLA 202) daje sinhroni pogled na naglasne, predvsem tonemske vzorce; izhaja iz primerjave z naglasnimi vzorci knjižnega jezika, kot so predstavljeni v uvodnem delu SSKJ, kjer glagolska tipologija temelji na naglasu v nedoločniku in sedanjiku.

ABSTRACT: The paradigm of verb forms (i.e., their inflectional and word-formation patterns) in the Upper Carniolan sub-dialect of Kropa (SLA 202) offers a synchronic overview of stress patterns, and especially tonemic patterns. This proceeds from a comparison with stress patterns in the standard language as presented in the introduction to the Standard Slovenian Dictionary (SSKJ), in which verbal typology is based on the stress in the infinitive and present tense.
\end{abstract}

1 Govor Krope na Gorenjskem (tudi točke 202 Slovenskega lingvističnega atlasa) se v marsičem razlikuje od sosednjih gorenjskih govorov, njegove posebnosti pa so predvsem na glasoslovni in besedni ravnini, manj v oblikoslovju. Vendar pa je tudi ta ravnina za jezikoslovno, tj. dialektološko, raziskovanje zelo zanimiva, saj prinaša nova spoznanja ne le o narečnih posebnostih v oblikospreminjevalnih vzorcih pregibnih besed, ampak tudi o tonematiki tega govora. ${ }^{1}$

V razpravi bo zato natančno predstavljen kroparski ${ }^{2}$ glagol oz. paradigmatika glagolskih oblik, tj. njegovih oblikotvornih in oblikospreminjevalnih vzorcev. Čeprav se na prvi pogled glagol kroparskega govora ne razlikuje bistveno od glagola v slovenskem knjižnem jeziku (če seveda zanemarimo fonološke posebnosti ter gorenjsko onemitev in oslabitev kratkih samoglasnikov), ${ }^{3}$ se ob primerjavi z Riglerje-

1 Članek je nastal na podlagi avtoričine raziskave (1993-1996) za doktorsko disertacijo Glasoslovje, oblikoslovje in besedišče govora Krope na Gorenjskem (Ljubljana, 1996) in njenih nadaljnjih raziskav za monografijo o tem govoru.

2 Glavna informanta za kroparski govor sta bila (ob mnogih drugih) Nace Blaznik (19122004) in Joža Eržen (1955) - prvič oba v devetdesetih letih 20. stoletja, drugič so bile oblike in tonemi preverjeni samo z J. Erženom leta 2006 in 2007. Avtorica članka sicer ni govorka kroparskega krajevnega govora ali gorenjskega narečja.

3 O njih je avtorica tega članka že večkrat pisala - o tem v Literaturi. 
vimi glagolskimi shemami za tonemski naglas knjižnega jezika, kot je predstavljen v prvi knjigi SSKJ (paragrafi 209-211), pokažejo nekatere zanimive posebnosti, predvsem pa velika zapletenost premen glagolskih tonemov v primerjanih glagolskih oblikah. ${ }^{4}$

S slovenskim glagolskim naglasom se doslej niso ukvarjali le raziskovalci sodobnega knjižnega jezika in njegove zgodovine (med njimi J. Toporišič, J. Rigler, M. Šekli), ampak tudi raziskovalci narečij, saj prav taka "/.../ obravnava (naglasnega) oblikoglasja /.../" lahko močno obogati "/.../ naše poznanje slovenskih narečij, to pa bi prispevalo $\mathrm{k}$ tipologiji in morda tudi k odkritju sedaj zakritih skupnosti in razlik med našimi narečji." (Toporišič 1990: 106.) Namen te razprave je zato ne le predstavitev narečnih paradigmatskih in naglasnih značilnosti kroparskega glagola, ampak tudi omogočenje primerjave s knjižnim jezikom in drugimi narečji, katerih glagol je že predstavljen na tak način. Tako je npr. V. Smole 1996 s svojim prispevkom o tonematiki glagola $\mathrm{v}$ dolenjskem šentrupertskem govoru želela opozoriti, "/.../ kako samosvoje, razvojno žive in s tem jezikovno neprecenljive naglasne sisteme ohranjajo slovenska narečja /.../" (prav tam: 286), T. Jakop 2003 pa je na tak način predstavila štajerski ložniški govor in ugotovila, da se "/r/azvojne tendence v smeri štajerskih tipoloških značilnosti /.../ ne ujemajo s splošnim sociolingvističnim prepričanjem, da se narečja približujejo knjižnemu jeziku" (prav tam: 22-23).

\section{Tvorba in delitev glagolskih oblik}

Tvorba in raba oblik glagolskega časa, vida, načina in naklona se v kroparskem govoru ne razlikuje od slovenskega knjižnega jezika, le pretekli pogojnik je tu precej pogosto rabljen, npr.: Če b 'jest i'mou dnẹ̀:uno, b_bla x mə'nə šla. Tṫ:zga sam 'mọu za spomì:'n, da ga b_biu ứt:du, kokọ́: i narjè:n 'Če bi jaz imel dnevno (sobo), bi k meni šla. Tistega sem imel za spomin, da bi ga (bil) videl, kako je narejen.' Moški in ženski spol sta $v$ kroparskem govoru dobro ohranjena, $z$ dvema posebnostima: dvojina ženskega spola polnopomenskega glagola je enaka množini ženskega spola (v pomožnem glagolu biti pa je dvojina ohranjena, npr. Pù:nce sta stanvá:le 'kar domàr. 'Dekleti sta stanovali kar doma.'), samostalniki srednjega spola (oziroma levi pridevniški prilastki ob njih) pa se v ednini in dvojini maskulinizirajo, v množini pa feminizirajo, tudi glagol v povedku, ki se v spolu, številu in osebi ravna po osebku, dobi ustrezno končnico za spol (v ed. in dv. moškega spola, v mn. pa ženskega spola), npr.: Sọ̀nnce i potem'noụ. 'Sonce je potemnelo.' Kolẹ̀nna mam potọ̀zučene. 'Kolena imam potolčena.' Povedek v srednjem spolu ednine je ohranjen ob t. i. splošnem osebku tọ̀', úse, npr.: Tọ̀r i blo/bla pa to'kə. 'To je bilo pa tako.' Čṫst u'se i bla za'nəč. 'Čisto vse je bilo zanič.' Tokọ̀: pa (tọ̀:) na bọ̀z šlla. 'Tako pa to ne bo šlo.' Z'la i ga:Rmẹ́:l. 'Zelo je grmelo.' 'Ko pa i blọ́?? 'Kaj pa je bilo?' A $i$ bla ydọ̀? 'Ali je bilo hudo?'.

Tako kot slovenski knjižni jezik tudi kroparski govor dela velelnik, deležnik

${ }^{4}$ Na ta način so narečni glagol obravnavali tudi V. Smole, T. Jakop in P. Weiss (glej Literaturo). 
na -č (ki je redek in se rabi kot pridevnik, npr. pojọ́ča skRt́nnca) ter deležji na -č in -e (ki sta tudi rabljeni redko, in sicer le kot izglagolski načinovni prislov, npr. 'KaR stojẹ: sam pojẹ:du. 'Kar stoje sem pojedel.') iz sedanjiške osnove; namenilnik, opisni deležnik na -l ter deležnik na -n/-t (ki se rabi predvsem kot levi pridevniški prilastek ali povedkovo določilo) in deležnik na -ši (ki je redek in rabljen le kot levi pridevniški prilastek, npr. bì:uša žẹ́:na) pa iz nedoločniške osnove (medtem ko se deležje na -ši v kroparskem govoru ne rabi). Deležniki stanja na - $l$ in - $n /-t$ se rabijo in pregibajo kot pridevniki in kot izpridevniški povedkovniki (npr. Predẹ́lane stró:je smo pó:i predà:jal. 'Predelane stroje smo potem prodajali.' UU'sa so žẹ zbrá:n. 'Vsi so že zbrani.')

Nedoločnik ima v kroparskem govoru vedno končaj -t, vendar je iz mesta in dolžine naglasa mogoče sklepati, da poznajo tako dolgi (uzẹ́:t, zauozlá:t, zdẹ:t, žuẹ:t) kot kratki nedoločnik (gouó:Rt, dá:Ržat, mó:lt, poló:mt, zaslú:žət, nó:sat, kú:pat). V večini glagolskih tipov se govori kratki nedoločnik (naglas ni na priponi, npr. klt́:cat, oz. je naglašeni samoglasnik v priponi kratek, npr. ig'Rat) - podrobneje o tem v Pregledu glagolov po vrstah/tipih.

Namenilnik se rabi ob glagolih premikanja. Končuje se na $-t /-\check{c} t$ (tudi $-s ̌ t$ ) in je

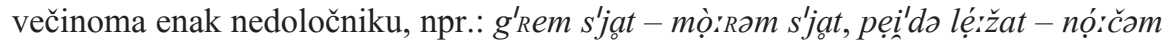
lẹ:žat, prí:t uečẹ:rjat - začnt̀'mo uečẹ:Rjat, se g'Rem zgouó:Rt-tRẹ́:ba se i zgouó:Rt, mo šlla žàrgat - mo nẹ:xal žàrgat, 'pẹ:ri že kú:xat 'pojdi že kuhat'-nt́: trẹ́:ba kúxxat, včasih (podrobneje o tem v Pregledu glagolov po vrstah) pa se od njega razlikuje v naglasu (tonemu), npr.: kouárt (nedoločnik) - kouà:t (namenilnik), pásst (nedoločnik) - pàsst (namenilnik), spá:t (nedoločnik) - spà:t (namenilnik), delt́t't (nedoloč-

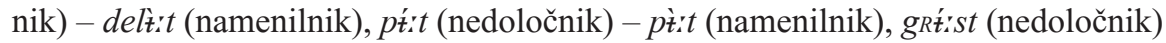
- gRt̀ist (namenilnik), pa:rjẹ:st (nedoločnik) - pa:rjẹ:t (namenilnik), uzẹ́:t (nedoločnik) - uzẹ̀:t (namenilnik), pé:čt (nedoločnik) - pèrčt (namenilnik) itd.

\section{Spregatveni vzorci glagolov}

V nadaljevanju glagol prikazujem tako, kot je predstavljen v Shemah za dinamični naglas in oblikoslovje ter v Shemah za tonemski naglas v Uvodu Slovarja slovenskega knjižnega jezika I (Ljubljana, 1980, str. XXXVIII-L in LV-LVIII), posebej pa so prikazani še brezpriponski glagoli - sheme so seveda prilagojene kroparskemu govoru. ${ }^{5}$ Samo pri prvem glagolu je naveden celotni pregibnostni vzorec, v nadaljevanju pa ob nedoločniku navajam še opisni deležnik na $-l$ (m. sp. ed., ž. sp. ed., m. sp. mn.), namenilnik in deležnik na $-n /-t$ (m. in ž. sp. ed.) ter povedni sedanjik (1. os. ed., 3. os. mn.) in velelnik (2. os. ed., 2. os. mn.).

5 (Jakostni) naglas na kratkem samoglasniku v naslednjih shemah v skladu s slovensko dialektološko transkripcijo označujem z znakom ' pred soglasnikom pred naglašenim samoglasnikom, dolžino samoglasnika pa z znakom : za samoglasnikom. Tonem dolgih samoglasnikov je natančneje prikazan v Pregledu glagolov po vrstah $-\mathrm{s}$ krativcem nad naglašenim samoglasnikom je označen cirkumlektirani samoglasnik, z ostrivcem pa akutirani. Narečno gradivo je zapisano z vnašalnim sistemom in pisavo ZRCola, ki ju je na ZRC SAZU razvil dr. Peter Weiss. 


\subsection{Atematski/brezpriponski glagoli jẹesst, uẹérdot, dá:t, błt't, ito/'jot}

Glavni spregatveni vzorec brezpriponskega glagola jẹest 'jesti' za sedanjik je: jẹ́:-m, -s, -ø, je-'moljẹer-mo, je-s'teljẹ́:-ste, jejoli'doljẹer-jo, je-'ualjẹ́:-ua, je-s'tal jẹ́-sta, je-s'taljẹ́:-sta. Končaj -dov 3. os. mn. je kratek naglašen in je mogoč še pri glagolih uẹé:dat (uə'do) in i'tal'jat (gRe'do), ne pa tudi dá:t in bét't.

Glavni spregatveni vzorec za velelnik: jẹ̀--in-mo za 1. os. mn., -va za dv.; jẹ̀-inza 2. os. ed., -te za mn., -ta za dv.

Glavni spregatveni vzorec za opisni deležnik na -l: jẹ̀:du za m. sp. ed., jẹ́:dla za m. sp. mn., jẹ́:dla za m. sp. dv., jẹ́:dla za ž. sp. ed., jẹ́:dle za ž. sp. mn., jẹ́:dle za ž. sp. dv.

Namenilnik tega glagola je jẹ:sst, deležnik na - $n$ (m. in ž. spol) tega glagola pa je (po)jẹ:den- $\varnothing-a .^{6}$

Posebnosti sedanjiških oblik:

1. Glagol jẹ́st ima v 1. os. mn. in dv. lahko ohranjen - $d$ - v osnovi (verjetno po analogiji iz opisnega deležnika na -l): jed-'mo, jed-'ua. Tako tudi glagol uẹé:dət: uəd'ua.

2. Glagol uẹe:dat - uẹ́:m tvori velelnik s končnico -ø: uẹ́:t-ø.

3. Glagolu dá:t - dá:m v velelniku pred /i/ v podstavi oslabi samoglasnik /a:/: dẹ̀i $i-\varnothing / ' d e ̣ i-\varnothing$, dẹ̀ri-te.

4. Pomožni glagol bítt ima velelnik bọ́t-ø bọ́:d-mo/bodț'-mo. Sedanjiški spregatveni vzorec tega glagola je prikazan v uvodu - če je naglašen, je cirkumflektiran, dolžina naglašenega samoglasnika pa je odvisna od govornega ritma ('səm, 'sə, 'jel jèr; s'mo/smòr, s'te/stèr, 'so/sòr; s'una/suàr, s'ta/stàr, s'ta/stàr). Nikalne oblike tega

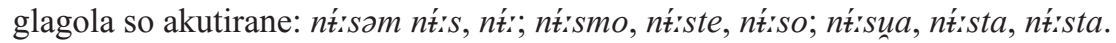

5. Glagol $i^{\prime}$ tal'jat ima sedanjik $g_{\text {Re- }} m$ gRe-'mo/gRér-mo in velelnik 'pẹi-ø/pẹ:in-ø/ peìnd-a, peíl-mo/pẹ̀i-mo.

Posebnosti nedoločniških oblik:

1. Glagoli bú́:t, i'ta, uẹ́:dat nimajo deležnika na -n/-t.

2. Glagol $i^{\prime} t \partial /$ 'jot ima naslednje oblike opisnega deležnika na -l (enako se premenjuje tudi opisni deležnik na -l predponskih glagolov prét:dət, Razt́t:dət se, pRet́tdat, uil'to/utítdat): za m. sp '̌sou, šl'la, -a in za ž. sp. -a, -e, -e.

3. Glagol $i$ 't seveda nima namenilnika.

4. Glagol bút t ima naslednje oblike opisnega deležnika na -l: za m. sp bà̀ $u, b^{\prime} l a l$

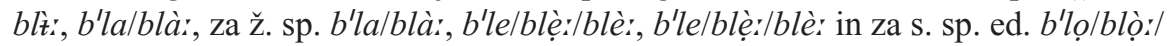
blọ́: (rabljeno ob prislovu).

5. Glagol dá:t ima opisni deležnik na -l dà:u, dá:la7 in deležnik na - $n$ dá:n-ø $-a-\varnothing$.

6. Glagol uẹ́:dat ima opisni deležnik na -l uẹ́:du, uẹ́:dla.

${ }_{6}$ Predponska/dovršna oblika deležnika na $-n$ je $\mathrm{v}$ kroparskem govoru pogostejša kot raba deležnika na - $n$ nedovršnih glagolov, zato so $\mathrm{v}$ tej in naslednjih preglednicah predpone takih deležnikov na - $n$ zapisane $\mathrm{v}$ oklepajih.

7 Srednji spol se v ednini maskulinizira, v množini pa feminizira, zato sta v nadaljevanju navedena le $\mathrm{m}$. in ž. sp. tako pri opisnem deležniku na $-l$ kot pri deležniku na - $n$ oz. $-t$. 
7. Predponski glagoli pojẹ́rst, najẹ́rst se ipd. imajo opisni deležnik na $-l \mathrm{~m}$. sp. ed. cirkumflektiran: pojẹ:du, najẹ: du se.

\subsection{Priponski glagoli}

I. Naglas na istem zlogu v nedoločniku in sedanjiku

A. Naglas ni neposredno pred $-\boldsymbol{t} i$ in $-\boldsymbol{m}$ (ni na glagolski priponi)

Tip IA1 - Glagoli na -ati -am oz. -at -am (kú:xat kù:xam; zí:dat zí:dam; žàrgat žà:gam)

Tip IA2 - Glagoli na -ati -im oz. -at -om (šlt'šsat šlt:'̌šm)

Tip IA3 - Glagoli na -ati -em oz. -at -em (klț́cat klț:čem; smẹ́:jat se smé:jem se; kolẹ:'dvat kolẹ:djem)

Tip IA4 - Glagoli na -iti -im oz. -t/-ət -əm (nastá:unt nastàruam; lú:šət lú:šəm; spọ̀:uðant spọ̀:unəm)

Tip IA5 - Glagoli na -niti -nem oz. -ant -nem (sttí:sant stì:snem; potẹ́rgant potẹ́rgnem)

Tip IA6 - Glagoli na -eti -im oz. -ət -əm (ứt:dat ùt:'dam)

B. Naglas je neposredno pred $-\boldsymbol{t} i$ in $-\boldsymbol{m}$ (na glagolski priponi) igrà:m)

Tip IB1 - Glagoli na -'asti -'arm oz. -'a:t/'at -'a:m (izdá:t izdá:m; ig'rat/igrá:t

Tip IB2 - Glagoli na -'a:ti -'ím oz. -'a:t -'̇́:m (spá:t spú:m)

Tip IB3 - Glagoli na -'a:ti -'em oz. -'ast -'em (pa:Ržgá:t pa:Rž'gem)

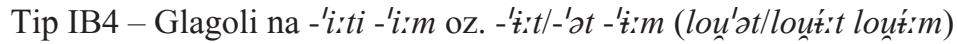

Tip IB5 - Glagoli na -ệti -'irm oz. -'ẹ:t -'t:m (žuẹ:t žutú:m)

Tip IB6 - Glagoli na -'ẹ:ti -'em oz. -'ẹ:t -'em, -'ẹ:ti -'nem oz. -'ẹ:t -'nem, -'ẹ:sti -'em oz. 'ẹ:st 'em (žrẹ́:t ž'Rem; napẹ́:t nap'nem; snẹ́rst s'nem)

Tip IB7 - Glagoli na -'ẹ:ti -'ẹ:m oz. -'ẹ:t -'ẹ:m ((smẹ:st) smẹ:m)

Tip IB8 - Glagoli na -'ẹ:ti -'a:m oz. -'ẹ:t -'a:m (imẹ́:t imà:m)

C. Naglas na istem zlogu $v$ nedoločniku in sedanjiku, toda neposredno pred -ti oziroma -či in ne neposredno pred $-m$

a) Samoglasnik pred $-t i$

Tip ICa1 - Glagoli na -'a:ti -em oz. -'a:t -em (prestá:t prestà:nem)

Tip ICa2 - Glagoli na -'irti ali -'usti -jem oz. -'t't ali -'ust-jem (pountít pouńtjem; zabú:t zabì:jem; obú:t obù:jem)

Tip ICa3 - Glagoli na -'ẹ:ti -em oz. -'ẹ:t -em (unzẹ:t uná:mem; gRẹ́:t gRẹ:jem ...)

b) Soglasnik -s- pred -ti

Tip ICb1 - Glagoli na -'arsti -em oz. -'arst -em (párst pársem; kRárst kràrdem)

Tip ICb2 - Glagoli na -'ísti -em oz. -'t'sst -em (gRér'st gRt́:zem)

Tip ICb3 - Glagoli na -'ẹ:sti ali -'ọrsti -em oz. -'ẹ:st ali -'orst -em (zẹ:pst zẹ́:be; gọ́sst gọ́:dem; usẹ́:st se usẹ:dem se)

Tip ICb4 - Glagoli na -'ersti ali -'orsti -em oz. -'erst ali -'orst-em (nérst nérsem; bó:st bó:'dem) 
c) Glagoli na -či -em oz. - -št/-čt -em

Tip ICc - Glagoli na -či -em oz. -štt-čt -em (pé:čt pé:čem; stRétšst stré:žem; uุá:Ršt uạ̀:Ržem)

\section{Č. Naglas na istem zlogu $v$ nedoločniku in sedanjiku, toda ni neposredno pred $-t i$ in je neposredno pred $-m$ \\ Tip IČ1 - Glagoli na -ati -'ẹ:m oz. -at -ẹ:m (pouẹ́:dat pouẹe:m) \\ Tip IČ2 - Glagoli na -eti -'ẹ:m oz. -ət -ẹ:m (uẹ́:dot uẹ́:m)}

\section{Naglas na različnih zlogih $\mathrm{v}$ samem nedoločniku ali $\mathrm{v}$ nedoločniku in sedanjiku}

\section{A. Naglas na različnih zlogih v samem nedoločniku}

Tip IIA1 - Glagoli na -ati/-'a:ti -am oz. -at/'-at -am/-'a:m (šttéxat/štz'xat štté:xam/ štzxà:m)

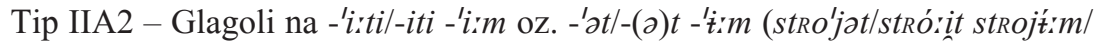
strọ́:jam)

\section{B. Naglas na različnih zlogih nedoločnika in sedanjika}

Tip IIB1 - Glagoli na -'a:ti -em oz. 'at/-'a:t -em (is'kat t́:šem; kouá:t kú:jem; s'jat/sjá:t sẹ̀:jem; kap'uat kapú:jem)

Tip IIB2 - Glagoli na -'iti -im oz. -'at -am (se'lat sẹ́:lam; popepe'lat popepẹ:lam)

Tip IIB3 - Glagoli na -'ẹ:ti -em oz. -'ẹ:t -em (pa:rjẹett pré:mem)

Tip IIB4 - Glagoli na -ati -'i:m oz. -at -'ṫ:m (dá:Ržat da:Ržť́tm)

Tip IIB5 - Glagoli na -iti -'ím oz. -(a)t-'̇́'m (gouór:Rt gouort́:m)

Tip IIB6 - Glagoli na -'ust -em (mnú:t métnem)

\section{Tip IA1 - Glagoli na -ati -am oz. -at -am}

a) v nedoločniku akut, $v$ sedanjiku cirkumfleks:

Nedoločniške oblike: nedoločnik kúxxat; opisni deležnik na $-l \mathrm{~m}$. sp. ed. kú:xou-ø, mn. kú:xal-ø, dv. kú:xal-a, ž. sp. ed. kúxxal-a, mn. kú:xal-e, dv. kú:xal-e, s. sp. ed. kúxxal-ø (rabljeno ob prislovu); namenilnik kúxxat; deležnik na -n (s)kùxxan-ø-a ø.

Sedanjiške oblike: sedanjik kù:xa-m, -š, -ø; -mo, -te, -jo; una, -ta, -ta; velelnik: kú:xẹi-ø; mo, -te; -ua, -ta.

Nekaj glagolov, ki gredo v ta tip: bá:Rskat, bó:nat 'zapravljati', détxat, dó:Rzat 'drzati, strgati', gọ́:ncat 'stepati testo', kú:kat, lopú:tat, (na)bú:tat, (na)fá':rcat, ${ }^{8}$ (pa:r)dẹ́:lat, (po)dẹ́lat, (po)glẹ́:dat, (po)jệ:nat, (po)pộ:kat, posẹ́:dat, ${ }^{9}$ (po)séekat,

8 Navajamo primere iz gradiva. Glagoli, ki se v kroparskem govoru lahko rabijo tudi brez predpon, imajo predpone $\mathrm{v}$ oklepajih.

9 Glagoli, ki se v kroparskem govoru ne rabijo brez predpone (oz. tega ne potrjuje zbrano gradivo), so v seznamih zapisani s predpono brez oklepajev. 
potá:plat, (pre)glẹ́:dat, presẹédat, (Ras)kúxxat, (Ras)sẹ́kat, smá:rkat, (s)sérkat, (s)tá:rgat, (pre)tá:rgat, uobt́:rat, (uo)glẹ́:dat so, (u)sẹ́:kat, (za)dẹ:lat, (za)glẹ:idat, (za)kú:xat, (za)sẹ́kat, (z)dẹ:lat, (z)glẹ:dat, (z)Rú:kat.

Posebnosti:

1. Glagol glẹ:dat ima velelnik glệin-ø -te ali lẹrin-ø -te. Tako tudi predponski glagoli.

2. V velelniku imajo nekateri od teh glagolov ob končaju -ẹi-ø za 2. os. ed. lahko tudi končaj -i/-ø, npr.: čárkat-čárkẹilčàrki/čàrk.

3 . V ta tip gredo tudi glagoli, ki v opisnem deležniku na $-l$ spremenijo mesto naglasa, in sicer je naglas v m. sp. mn. in dv., s. sp. ed. (akut je tu ohranjen) ter v ž. sp. (oblike so tu cirkumflektirane) proti koncu besede, npr. nedoločnik dRt́: ̌́at, opi-

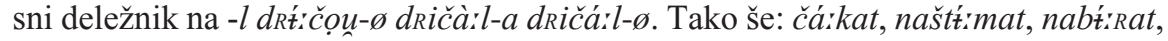

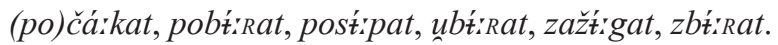

\section{b) v nedoločniku in sedanjiku akut:}

Nedoločniške oblike: zí:dat; zí:dou-ø zí:dal-a zí:dal-ø; zí:dat; zí:dan-ø-a.

Sedanjiške oblike: zí:da-m -jo; zídẹi-ø-te.

Spregatveni vzorec je enak kot v tipu IA1a, le vse oblike so akutirane. V ta tip (IA1b) gredo glagoli: bé'uat, fẹ́rxtat, izlọ́čat, jú:žnat, mó:ygat 'valjati s kuhinjskim valjarjem', načmár:Rkat 'oklofutati', nadomẹ́rščat, nagọ́:lbat '(na)tepsti' ó:fnat, (po)štt́:rkat, pogrú:ntat, popú:šat, porú:kat, (po)tẹ́:nstat, prežṫulat, pú:ntat se, Rá:intat, Rt́:ygat se 'prepirati se', Rt́xxtat 'urejati', scá:mat se 'utruditi se', spomé:nat se, (s)tẹ:nstat, šẹ́:ykat, ukuá:rjat se, uprá:ulat, uré:jat, ubráritat, ukuá:rjat se, uporá:blat, zamjẹ́:rkat, zavẹ́:dat se, zt́:dat, zbréxxtat, zjẹ́:zat, zlá:inat 'spoditi iz postelje', (z)nú:cat, zú̀'rtat, žó:kat.

\section{Posebnosti:}

1. Nekateri glagoli imajo v opisnem deležniku na $-l$ m. sp. mn. in dv., ž. sp. vseh števil ter s. sp. ed. mesto naglasa bolj proti koncu besede, pri tem je v oblikah za m. in s. sp. ohranjen akut, oblike ž. sp. pa so cirkumflektirane, npr. nedoločnik pomárgat, opisni deležnik na -l: pomárgou-ø pomagà:l-a pomagá:l-ø. Primeri iz gradiva: zabú:jat - m. sp. mn. zabijá:l, pú:cat - m. sp. mn. pucá:l, strẹ́lat - m. sp. mn. strelá:l, štrí:kat - ž. sp. ed. štrikàrla, (po)mẹ́: ̌̌at - ž. sp. ed. (po)mešààla, zapt́rskat - m. sp. mn. zapiská:l, (s)plá:čat - s. sp. ed. (s)plačá:l, posprá:ulat ž. sp. ed. pospraulà:la, postá:ulat - m. sp. mn. postaulárl, Razbí:jat - Razbijàrla (̌̌. sp. ed.), zmẹ́:rjat - m. sp. dv. zmerjá:la itd. Tako še: blt́rskat se, dobt́zuat, xRú:stat, izzt́:vat, jọ́:kat se, járgat se, lé:tat, má:xat, nabt́:jat, naft:lat, nagá:jat, nalt́:jat, namá:xat, naprá:ulat se, naứt:jat se, naudá:rjat 'na poseben način kovati s pomočjo drugega kovača', parprárulat, partís'skat, parršpáriat, plú:uat, počtzuat,

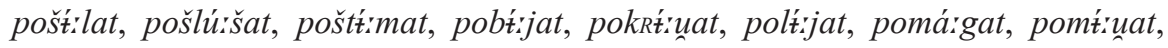
(po)mẹ́ršat, ponú:jat, (po)plá:čat, (po)prá:šat, (po)prárskat, poprá:ulat, (po)pú:cat, port́unat, posprá:ulat, postárulat, potálat, pouárlat, (pre)mẹišat, (pre)píxxat, Rassá:jat, Rastá:lat, Razbí:jat, sestá:ulat, sezú:uat, skRt́:uat, splá:čat se, spú:šat,

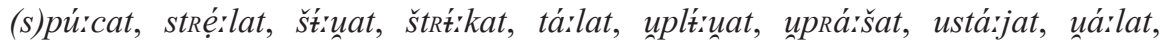

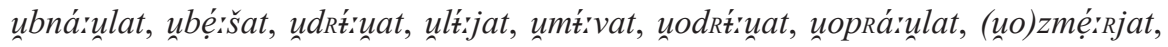


uRtískat, (za)špt́:lat, (za)já:gat, zalt́tuat, (za)mẹ́nat, (za)ptéskat, zaprá:ulat, zt́:dat, zbt́:jat, (z)járgat, zlt́tjat, (z)mẹ́šsat.

2. V velelniku so nekateri teh glagolov ob končaju -ẹi-ø za 2. os. ed. akutirani, ob končaju $i /-ø$ za 2 . os. ed. pa cirkumflektirani, npr. nedoločnik pošlú:šat, velelnik: pošlú:šși-ø/pošlùiš-ø pošlú:šęn-te/pošlùiš-te.

3. Nekateri glagoli imajo tudi v velelniku mn./dv. naglas bolj proti koncu besede (spremeni se tudi tonem), npr. nedoločnik pRá:šat, sedanjik pRá:ša-m pRá:ša-jo, velelnik prá:šẹi-ø prá:šệi-telprašà:i-te.

\section{c) v nedoločniku in sedanjiku cirkumfleks:}

Nedoločniške oblike: žà̀gat; žàrgou-ø žà'gal-a -ø; žà'gat; (z)žààgan -a.

Sedanjiške oblike: žà:ga-m-jo; žà:gẹi-ø -te.

Spregatveni vzorci so enaki kot $\mathrm{v}$ tipu IA1a, le tonem je $\mathrm{v}$ vseh oblikah cirkum-

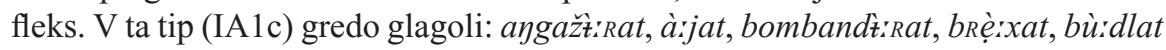

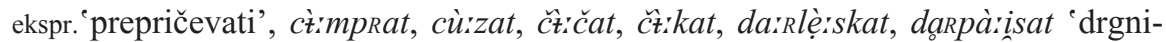
ti', debatt̀':Rat, dRẹ̀:fat 'drseti', ft̀:lat, fRà̀jat 'opravičiti služenja vojski', fRù̀:štkat 'zajtrkovati', fù̀cat, fù:rat, grà:užat se 'studiti se', gù:ncat 'gugati', guẹ̀:Rat 'trajati', izgọuàrrjat, jà:mrat, jà:xat, kapt̀̀'Rat, kà:šlat, klọ̀ffat, kolẹ:ncat 'sankati se z

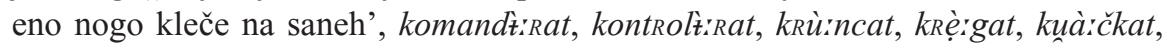
lì:čkat, mọ̀ussat, maš̀̀trat, mast̀̀:Rat, mà:lčat, mà:rat, mà̀trat, mjà:ukat, (na)bù:dlat 'natlačiti, napolniti z nadevom', (na)fù̀trat, (na)gà̀rbat, naklà:dat, namà:kat, (na)mà̀lat, napà:dat, napẹ:nat, (na)Rà̀bat, narobọ̀ttat, nauelṫ̀čat se, nẹ̀xat, (par)lì̀mat, parlẹ:gat se, pà̀dat, plà:ušat, plà:uat, plombt̀̀rat, plẹ̀:zat, požè̀:Rat, počẹ:nat, (po)cù̀krat, podà̀jat, podè̀rat, pogà:nat, (po)glt̀:xat, pogouà̀rjat, pomà:kat, (po)mò:kat 'namočiti kruh v omako', (po)mùrckat se, pomẹ̀tat, (po)Rè̀bat, (po)Rì̀xtat, potẹ:pat, (po)xù:šat 'pihniti v roke, da se ogrejejo', (po)xẹ̀rcat se, prọ̀:bat, predà:jat, (pre)flà:ncat 'presaditi sadiko', (pre)gà̀rbat, preklà:dat, premì̀kat, prenà:šat, preuà:žat, preuà:jat, prẹ̀:klat se, prẹ̀:mzat, pù:mpat, Rọ̀:fkat, Račù:nat, Rabù̀tat, Rasxà̀îkat, (Raz)žà 'gat, Razgà̀nat, Razvà̀žat, Rà̀imat se 'prilega-

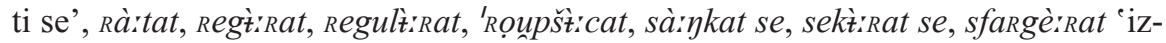
prašati', skà'usat, sklà:nat se, slt̀̀:kat, smù:čat se, snẹ̀:mat, spò:kat, sRẹ̀:čat, strẹ̀:nat,

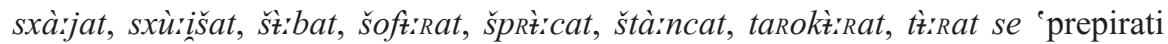

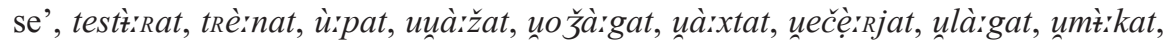

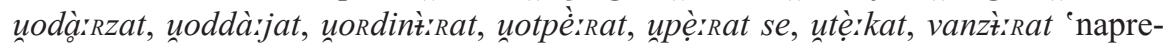
dovati', và̀ndRat, (z)žà rgat, (za)žlà̀ifat 'zavreti', (za)šsà̀u úbat, zagọ̀'ncat 'preveč stepsti testo', zajebà̀uat, zaxà̀klat/zakàxxlat, (za)là'ufat, (za)prẹ̀:mzat, zapẹ̀rnat, zapè̀:Rat, zbà̀dat, (z)bẹ̀rgat, zgà̀nat, zgouà̀rijat se, (z)mà̀ykat.

Posebnosti:

1. Tako se sprega tudi glagol mọ̀rRam (nedoločnika tega glagola - mọ̀rRat(i) -

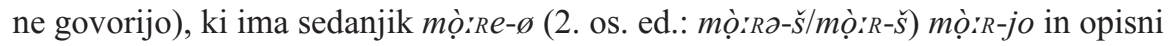
deležnik na -l mọ̀'gu-ø mọ̀gl-a mọ̀gl-ə/mọ̀gวal-ø.

2. Nekateri glagoli imajo v opisnem deležniku na $-l$ m. sp. mn. in dv., s. sp. ed. ter ž. sp. vseh števil lahko mesto naglasa bolj proti koncu besede, pri tem so oblike za m. in s. sp. akutirane, oblike za ž. sp. pa cirkumflektirane, npr. (iz gradiva): 
pogà:nat - m. sp. dv. poganá:la - ž. sp. ed. poganà:la, potẹ:pat se - m. sp. mn. potepáll se.

\section{Tip IA2 - Glagoli na -ati -im oz. -at -əm}

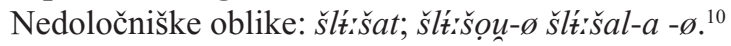

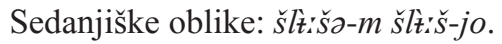

\section{Tip IA3 - Glagoli na -ati -em oz. -at -em}

Ti glagoli v sedanjiški podstavi mehčajo soglasnik pred končajem *-jem, npr.: -c-at : -č-em (klt́́ccat), -s-at : -š-em (pt́'sat), -z-at : -ž-em (ué:zat), -d-at : -j-em (glọ́:dat), -k-at : -č-em (ská:kat), -p-at : -pl-em (kó:pat), -m-at : -ml-em (dRẹ́:mat), -u-at (-ovati) : -j-em (-ujem) (ué:ruat, pẹ́stvat), -u-at : -ul-em (dẹ́ruat 'devati'). Glagoli tega tipa imajo vedno kratki nedoločnik (medtem ko je v knjižnem jeziku mogoč tudi naglas na priponi -ati).

a) akut v nedoločniku, cirkumfleks v sedanjiku:

Nedoločniške oblike: klt́:cat; klt́́cọu-ø klicà:l-a klicá:l-ø; klt́:cat; (pRe)klt́́can-ø $-a$.

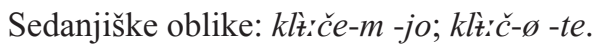

Ti glagoli imajo v opisnem deležniku na $-l$ m. sp. mn. in dv., s. sp. ed. ter ž. sp. vseh števil mesto naglasa bolj proti koncu besede, pri tem so oblike za m. in s. sp. akutirane, oblike za ž. sp. pa cirkumflektirane. Tako še: (na)bá:sat, (na)márzat,

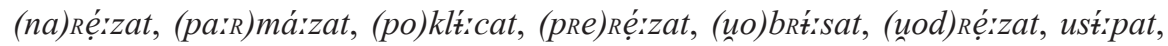
(z)bársat, (z)brís'sat.

\section{b) akut v nedoločniku in sedanjiku:}

Nedoločniške oblike: smẹ́:jat se; smẹ́:jou-ø se (je) smejàrl-a se (je) smẹá:l-ø (so) se; smẹ:jat; (na)smejá:n-ø-a.

Sedanjiške oblike: smẹ́:je-m se -jo se; smẹ́:i-ø se -te se.

Tudi ti glagoli imajo v opisnem deležniku na $-l$ m. sp. mn. in dv., s. sp. ed. ter ž. sp. vseh števil mesto naglasa bolj proti koncu besede, pri tem so oblike za m. sp. ed. in mn. akutirane, oblike za ž. sp. ed. pa cirkumflektirane, npr. pís'sat - opisni deležnik na -l pú:sọu-ø pisàrl-a pisá:l-ø, glọ́:dat - opisni deležnik na -l glọ́dọu-ø glọ́:dal-a/glodàrl-a glọ́dal-ø/glodá:l-ø, kó:pat, opisni deležnik na -l kó:poụ-ø kopà:l-a kopá:l-ø. Tako tudi predponski glagoli, npr.: napt́sat, popt́sat, potpt́:sat, prepísat, zapt́sat; zasmé:jat se, nasmé:jat se, posmẹ́:jat se; napé:lat, parpẹ:lat; ká:zat, poká:zat, uká:zat; klé:pat, sklé:pat; nauẹ:zat, udvẹ:zat, uẹ:zat, zauẹe:zat, zvẹ:zat; pokó:pat, prekó:pat, skó:pat, uokó:pat; ská:kat, poská:kat; sú:kat, zasú:kat;

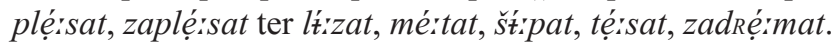

Posebnost: nekateri glagoli imajo v opisnem deležniku na - $l$ lahko naglas bolj proti koncu besede tudi v m. sp. ed., ki je tedaj cirkumflektiran, mn. in dv. m. sp. pa sta akutirani, npr. dẹ́unat (in predponski glagoli), opisni deležnik na $-l \mathrm{~m}$. sp.

${ }^{10}$ Oblike, ki se v kroparskem govoru ne rabijo, so v teh preglednicah izpuščene. 
ed. deuà̀u-ø/dẹ́:uou-ø, mn. deuá:l-ø, dv. deuá:la, ž. sp. ed. deuà:l-a, mn. in dv. deuà:l-e, s. sp. ed. deuá:l-ø.

\section{c) cirkumfleks v nedoločniku in sedanjiku:}

Nedoločniške oblike: kolẹ̀:dvat; kolẹ̀:duou-ø kolẹ:dual-a -ø; kolẹ̀duat; (po)kolẹ:duan-ø - $a$.

Sedanjiške oblike: kolẹ:dje-m -mo; kolẹ̀:duẹi-ø -te.

$\mathrm{V}$ tej skupini so večinoma glagoli na -ovati -ujem oz. -uat -jem (ti so v kroparskem govoru za izražanje ponavljalnosti in trajanja pogostejši kot v knjižnem

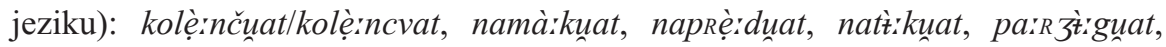
pa:Rpọ̀rguat se, pogà̀rkuat, posRẹ̀:dvat, potẹrguat, splà:kuat, stì̀kuat, uodlẹ̀:tvat,

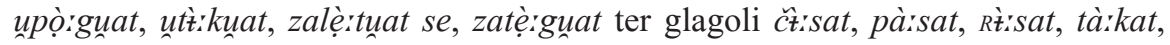
zarì̀sat.

\section{Tip IA4 - Glagoli na -iti -im oz. - $t /-\partial t$-om}

Glagoli tipa IA4 (in tudi IB4) imajo v deležniku na - $n$ glede na končaje nedoločnika naslednje oblike (navajam le obliko za m. sp. ed.): -šat -šen (prestrá:šsat - prestráišen), -čat -čen (pọ́rčat - pọ́rčen), -tat -ten (čú:tat - (ob)čúutten), -dat -den (začú:dat - začú:den), -jat -jen (máiint - (uo)márjen), -žət -žen (slú:žat (za)slú:žen),-nt-nen (žé:nt-(uo)žẹ́:nen),-lt-len (žú:lt-(uo)žú:len),-Rat-Rjen (mẹ́:Rt(z)mẹ́:Rjen), -sat -šen (nórsat - (po)nợišen), -zat -žen (uórzat - (z)uọợžen), -dat -jen (čẹ́:dat - (uo)čẹ́:jen), -tat -čen (umlá:tat - umlá:čen), -stat -ščen (čtéstat (uo)číšščen), -bat-blen (pogRá:bat-pogRá:blen), -ut -ulen (napRá:unt-naprá:ulen), -mat -mlen (poló:mt - polọ́:mlen), -pat -plen (lú:pat - (uo)lú:plen), -salt -šlen (premítsalt - premíšlen), -tat -tlen (Rasiuẹ́:tat - Ras'uet'len), -tat -tnen (bú:tat bú:tnen).

Kakovostna premena naglašenega samoglasnika (nedoločnik - sedanjik) je pogosta, npr.: xó:dat - xọ́:dam, žé:nt selžẹ́:nt se - žẹ́:nam se, is:é:lt - is:ẹ́:lam, mó:lt - mọ́llam, nó:sat - nọ́:sam, pRórsat - prọ́rsam, poló:mt - poló́rmam, pomó:čat pomọ́:čam, vó:zat - vọ́:zam.

Izgovor sklopa zvočnik + zvočnik, nastalega zaradi onemitve ponaglasnega in izglasnega samoglasnika $i$ v priponi nedoločnika, se olajša s polglasnikom, npr.: napọ́:ůnt 'napolniti' - napọ̀:uñm.

\section{a) akut v nedoločniku, cirkumfleks v sedanjiku:}

Nedoločniške oblike: nastá:ut; nastá:unu-ø nastá:ull-a -ə; nastá:unt; nastà:ulen-ø $-a$.

Sedanjiške oblike: nastà:uð-m nastà:u-jo; nastá:u-ø -te.

Tako še: bú:nt se, bú:tat, čtistot, čúdat se, da:ruár:Rt, má:iñt, našẹ́:mt, (na)já:ut, naprá:ut, naudá:Rt, pọ́:čt, pa:rstílt, parprá:ut, pt́:lt, pogRá:bat, pokú:sat, (po)mt́:salt, (po)mẹ́rt, ponasRẹ́:čat se, poprá:ut, poskúsat, postárut, pozdrázut, prá:ut,

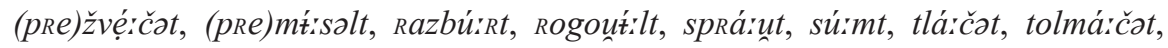

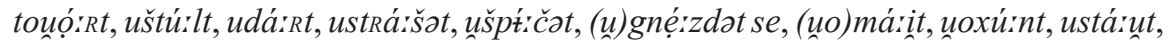
(za)cart́ntnt, zaprá:unt, zdRárunt, (z)mé:salt sa. 
Posebnosti:

1. Nekateri glagoli imajo $\mathrm{v}$ opisnem deležniku na $-l \mathrm{v}$ vseh oblikah razen $\mathrm{v}$ m. sp. ed. naglas na priponi, npr. izRá:zat, opisni deležnik na -l: izRá:zu-ø izraż̀̀ll-a izrazt́:l-ø. Tako še: brọ́:čat, dá:unt, gá:zat, pá:čat se, (po)grá:bat, (po)skó:čat, Rá:nt, (za)gRá:bat, zaklú:čat, zastọ́:pat, (z)gRárbat.

2. Glagol mú:salt ima v 2. os. ed. sedanjika lahko dve obliki: mìrsləš in mì: ̌̌ zadnja se uporablja predvsem v vprašalnih povedih, npr.: Mt:ž, da ư se uẹ:ršs?

3. Glagol zastọ́:pat se ima v velelniku (razen v obliki za 2. os. ed.) naglas na priponi: zastop̀̀̇ta se (2. os. dv.) - taka oblika je cirkumflektirana.

4. Nekateri glagoli, ki se v osnovi končujejo s sklopom soglasnik + zvoč-

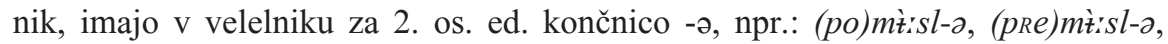

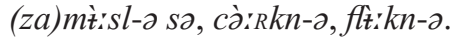

\section{b) akut $\mathrm{v}$ nedoločniku in sedanjiku:}

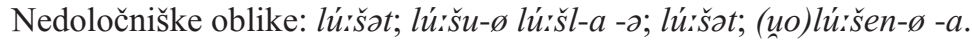

Sedanjiške oblike: lú:šs-m lúr:̌̌-jo; lú: ̌š-ø -te.

$\mathrm{V}$ tej skupini so večinoma glagoli, ki imajo kratki nedoločnik, tj. naglas na osnovi (v knjižnem jeziku so tu dolgi nedoločniki z naglasom na glagolski priponi), tako še: čú:tat, čẹ́:dat, lú:pat, (na)xlẹ́rstat, (s)krẹ́:tat, (uo)lú:šat, (uo)lú:pat, (za)kRẹ́:tat.

\section{Posebnosti:}

1. Večina glagolov ima $\mathrm{v}$ opisnem deležniku na $-l \mathrm{v}$ vseh oblikah, razen $\mathrm{v} \mathrm{m}$. sp. ed., naglas na priponi, npr.: xó:dat - xó:'du-ø xodt̀:l-a xodt́ll-ø. Tako še: brú:sat, čú:tat, dovó:lt, gọ́nt, xó:dat, issé:lt, mọ́:tat, mlá:tat, mó:lat, (na)cé:pat, (na)mó:čat, (na)nó:sat, (na)pọ́:uant, (na)pRórsat, (par)žẹ:nt, (po)ló:mt, (po)mó:čat, (po)mẹ́:nt, (рo)nó:sat, posọ́:dat, (po)svẹ:tat, (po)vá:bat, pozá:bat, pró:sat, (Ras)trọ́sat, Rá:bat, Rẹ́:šat, sposọ́:dat sa, (s)xó:dat, tú:ltltúllat, ulá:čat, (u)pú:lt, (u)žú:lt, uọ́:dat, (uot)kú:pat, uoxRá:nt, (za)bẹ́:lt, (za)cẹ́:lt se, (za)kú:rt, (za)lú:bat se, (za)mẹ́:sat, (za)slú:žat, (za)tọ:žat, (z)brọ́:dat, (z)bẹellt, (z)ló:mt, (z)mó:lt, (z)mẹ́:nt se, (z)nó:sat, (z)vó:zat.

2. Nekateri glagoli imajo lahko tudi v velelniku (ne v ednini) naglas na priponi, npr.: znó:sat-znó:s-ø znosì:-te

\section{c) cirkumfleks v nedoločniku in sedanjiku:}

Nedoločniške oblike: spọ̀:uənt; spọ̀:unu-ø spọ̀:uənl-a -ə.

Sedanjiške oblike: spọ̀:uñ-m spọ̀:ữan-jo; spọ̀:un-a spọ̀:ůn-te.

Tako še predponski glagoli, npr. zapọ̀ữ

\section{Tip IA5 - Glagoli na -niti -nem oz. -ont -nem}

a) akut v nedoločniku, cirkumfleks v sedanjiku:

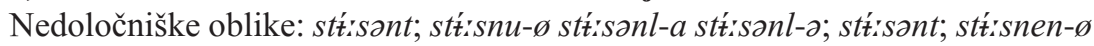
$-a$.

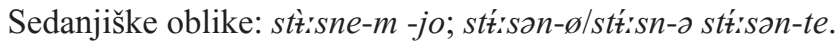

Tako še: cá:rkant, dá:Rgant, flí:kant, xó:pant 'zgrabiti', ká:usant, naštọ́:kant 'nabosti', (na)pt́xxant, pa:Rtí'sant, parsmọ́:dant 'prismoditi', podá:Rsant, podRt́tč̀nt, 


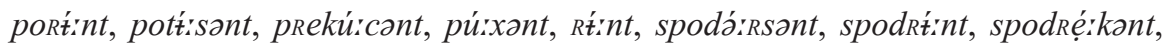

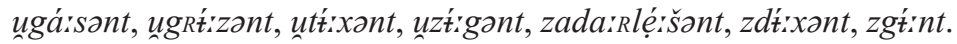

Posebnosti:

1. Glagol bá:Rcənt ima v 1. os. ed. sedanjika lahko naglas na glagolski podstavi (bà̀rrcnem), glagol bá:cant pa na glagolski priponi (bac'nem). V opisnem deležniku na -l je naglas običajno na priponi (bəc'nọ-ø bəcnì̀ l-a bacnt́:l-ø/báarRcənl-ə).

2. Glagol poklẹ́:kənt ima v opisnem deležniku na -l (v vseh oblikah razen v m. sp. ed.) naglas na priponi: poklẹ́:knu pokleknt̀:la pokleknt́:l.

3. V ta tip glagolov bi morda lahko uvrstili tudi glagol prí:dat 'priti':

Nedoločniške oblike: prt́: dət; pa:R'šou-ø pa:Ršs'l-a (kot atematski glagol $\left.i^{\prime} t \partial\right)$.

Sedanjiške oblike: prì̀:de-m pRì:'de-jo; prt́:t-ø pré:t-te.

\section{b) akut $v$ nedoločniku in sedanjiku:}

Nedoločniškeoblike:potẹ́:gənt;potẹ́:gnu-øpotẹ́:gənl-a/potegnì̀l-apotẹ́:ganl-al potegntíl-ø; potẹ́:gant; potẹ́:gnen-ø-a.

Sedanjiške oblike: potẹ́rgne-m -jo; potérgn-a/potẹ́rgan-ø -te.

Tako še drugi glagoli, ki imajo kratki nedoločnik, v knjižnem jeziku pa je mogoč oz. celo običajnejši dolgi naglašeni samoglasnik: gá:nt se, ná:gənt se, potá:kant, premá:kant, spotá:kant, sté:gant, usá:xənt, uogá:rant, zaklẹ́:nt, zapá:xənt, zatẹ́rgant.

Posebnosti:

1. Nekateri glagoli imajo v velelniku za 2. os ed. lahko končniški naglas, npr. (iz gradiva): umá:kənt - umá:kn-ə/umak'n-ə. Tako še: unbá:Rənt, pá:xənt.

2. Nekateri glagoli imajo v opisnem deležniku na $-l \mathrm{v}$ ed. m. sp. lahko naglas na priponi, npr. (iz gradiva): namá:kənt - namak'nọu. Tako še: pá:xənt, natá:kənt.

\section{Tip IA6 - Glagoli na -eti -im oz. -ət -əm}

a) akut $\mathrm{v}$ nedoločniku, cirkumfleks $\mathrm{v}$ sedanjiku:

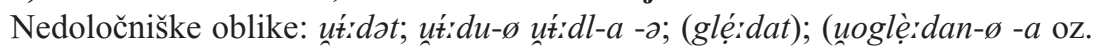
ù̀̀:'dən-ø dna). ${ }^{11}$

Sedanjiške oblike: ùì̀ddo-m ù̀̀:d-jo; (poglẹ́:in-ø-te).

\section{Tip IB1 - Glagoli na -'aiti -'a:m oz. -'a:t/'at -'a:m}

a) akut $v$ sedanjiku:

Nedoločniške oblike: izdá:t; izdà:u-ø izdá:l-a izdà:l-ø; izdà:t; izdá:n-ø -a.

Sedanjiške oblike: izdá:- $m$-jo; iz'dẹ-ø izdè̀i-te.

Gre za korenski naglas, saj je sem mogoče uvrstiti le predponske glagole iz atematskega glagola -dati (predá:t, uoddá:t).

\section{b) cirkumfleks v sedanjiku:}

(Zdi se, da imajo vsi glagoli tega tipa $v$ nedoločniku lahko (jakostni) naglas na kratkem samoglasniku ali akut na priponi -ati - naglas na kračini je vendarle običajnejši; navajam oblike, ki so izpričane v gradivu.) 


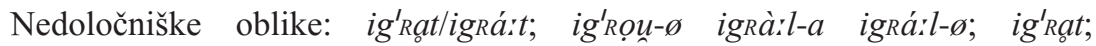
(za)igRá:n-ø-a.

Sedanjiške oblike: igràr-m -jo; ig'rệi-ø igRẹ̀ri-te.

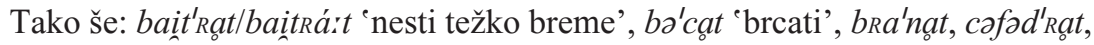
cmand'Rat/cmandRá:t 'stopicati', ček'lat/čeklá:t 'narahlo vreti', čes'nat, deuet'lat/ deuetlá:t jo 'hitro iti', (do)kon'čat, flaun'zat/flauzá:t 'besedičiti', fRa'tat 'drvariti na poseki', gol'fat/golfá:t, xlaišst'Rat/xlaišstrá:t 'nerodno hoditi', ig'Rat, jezi'kat, kla'fat, klam'bat 'nerodno hoditi', koš'tat 'stat', kofe'tat 'piti kavo', kolešt'Rat/koleštrá:t ' krivo hoditi, kobacati se', kra'cat, kreúlat/kreulá:t, kroxo'tat selkroxotá:t se, kuar'tat, lon'gat/longá:t 'mahati sem in tja, nihati', maưllat/maulá:t 'počasi jesti', mon'cat, meže'Rat 'tleti', mex'čat, paik'lat/paiklá:t 'vejati', (paR)xlaǐst'Rat, plan'kat/playká:t 'tolči, klepati', poštz'pat/poštzpá:t 'potresti, posipati', pobaiklat 'dogoreti', (po)klepe'tat, (po)maúlat/pomaulá:t, (po) Roun'nat, (pre)šstz'xat '(pre)lopatiti', Ropo'tat, (s)paikklat, (s)poz'nat/(s)poznárt, šan'tat, št'mat, ue'lat/uelá:t, z'nat, (za)uoz'lat) (za)uozlá:t, z'jat/zjá:t, (z)meš'kat/(z)mešká:t, (z)u'xat ' ${ }^{\prime}$ zuhljati', žgeč'kat.

\section{Tip IB2 - Glagoli na -'a:ti -'i:m oz. -'ast -'timm}

\section{a) akut v nedoločniku in sedanjiku:}

Nedoločniške oblike: spá:t; spàru-ø spá:l-a spà:l-ø; spà:t; (na)spá:n-ø -a.

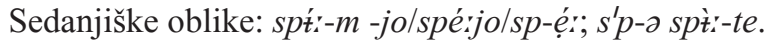

Tako še predponski glagoli, npr.: zaspá:t, naspá:t se.

Posebnosti:

1. Glagola stá:t in bá:t se imata v sedanjiških oblikah spremenjeno glagolsko

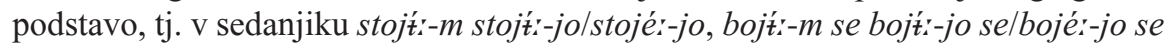
in v velelniku stọ̀i $i$-ø stọ̀:i-te, bọ̀rị-ø se bọ̀ríle se.

2. Ista dva glagola imata $\mathrm{v}$ ed. $\mathrm{m}$. sp. opisnega deležnika na $-l$ namesto pripone -u-ø $(<-l)$ pripono uu-ø in sta akutirana: stá:un, bá:un se.

3. V tem tipu glagolov je pogosta kratka oblika za 3. os. mn. sedanjika, npr. spẹ́:, bojẹ: se.

\section{Tip IB3 - Glagoli na -'asti -'em oz. -'ast -'em}

\section{a) akut v nedoločniku, kračina v ed. sedanjika:}

Nedoločniške oblike:pa:Ržgá:t; pa:Ržgà'u-ø pa:Ržgá:l-a pa:Ržgà:l-ø;pa:Ržgà̀t; pa:Ržgá:n-ø $a$.

Sedanjiške oblike: pa:Ržge-m pa:Ržgér-jo; pa:Rž'g-ə pa:Ržgt̀-te.

Tako še predponski glagoli, npr.: požgá:t, zažgá:t ter glagol dajá:t.

\section{Tip IB4 - Glagoli na -'irti -'irm oz. -'itrt/-'ot -'itm}

a) akutirana dolga ali kratka naglašena pripona v nedoločniku (navajam obliko, kakršna se pojavlja v gradivu) in akut v sedanjiku:

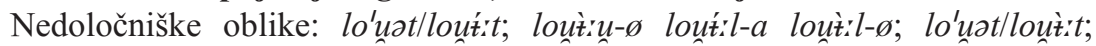
(u)loulé:n-ø-a/(u)loụllen-ø (u)loulé:n-a.

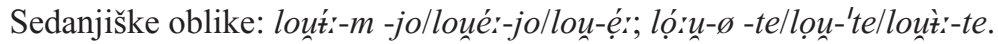

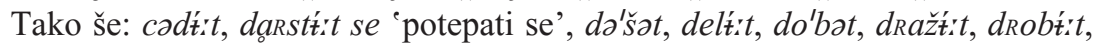

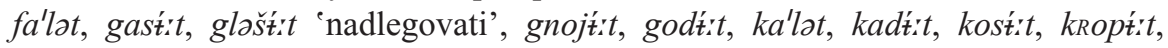




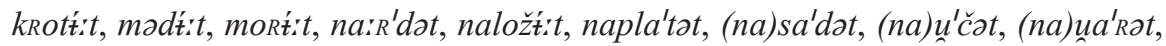

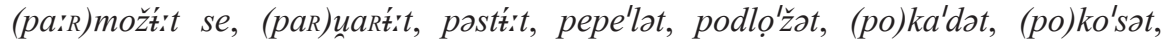

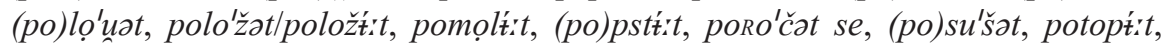
(pre)ce'dat, preta'lat, (Ras)kroptít se, (Ras)solt't, (Ras)tallat, (Raz)delt't, Razložt't,

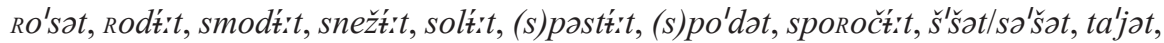

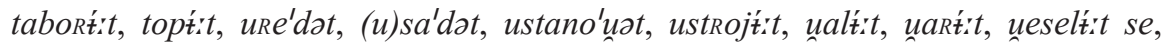
uglastít se, (u)možż:t, (uot)pastit:t, upokojtít se, zadarstí:t 'ozmerjati, grobo vzeti be-

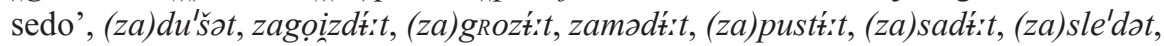
(z)bad'́t, zgabtít, zgodt't't, (z)gRa'dat, zgRe'šat, zložt't, zuartít, zvo'nat. Tako predponski kot brezpredponski glagoli se lahko pojavljajo z dolgimi in kratkimi nedoločniki, vendar glede tega ni nobenega pravila ( $s a^{\prime} d \partial t$-zasadt':t, usa'dot, nasa'dat;

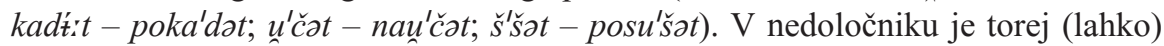
ohranjen akut.

Posebnosti:

1. V tem tipu glagolov (s sedanjikom na -t́tm) je pogosta kratka oblika za 3. os. mn. sedanjika (nekaj primerov iz gradiva), npr. dobẹ́r, dušẹé, godẹ́r, naRdẹ́r, Razdelẹ́: topẹ́:

2. Ti glagoli imajo poleg naglašene pripone $-t^{\prime}-\mathrm{v}$ needninskih oblikah tudi pripono -é:-, npr. kosérmo, cedé:te, loué:jo, naRdé:va, sadé:ta.

3. Nekateri glagoli tega tipa so $\mathrm{v} 1$. os. mn. sedanjika lahko naglašeni na kratkem samoglasniku v končnici, npr.: kost́:molkos-'mo, lout́t'-mollou-'mo, cedt́'-mol cad-'mo.

4. V opisnem deležniku na - $l$ je naglas pogosto na glagolski podstavi, ne na

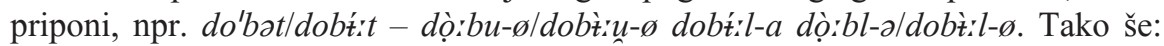

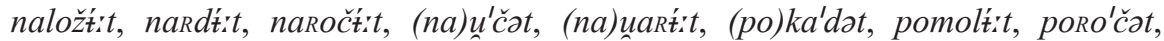

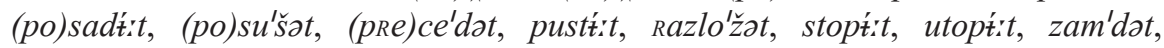
(za)podt́:t se, $(z a) s a^{\prime} d a t$, zgRe'šat, zgubút't.

\section{Tip IB5 - Glagoli na -'ẹtti -'ím oz. -'ẹ:t -'ìm}

a) akut v sedanjiku:

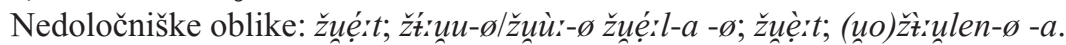

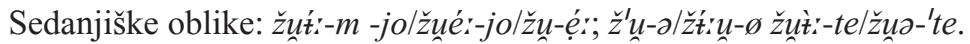

Tako še: bolẹ:t, cvetẹ:t (ta glagol gre lahko tudi v tip IB6a), čpẹ́:t, garmẹ:t,

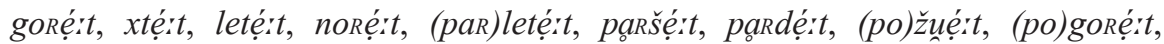
(po)temnẹ́:t, poxtẹ́:t, (pre)žuệ:t, (pre)xtẹ́:t, Rumenệ:t, sma:Rdẹ́:t, ta:Rpẹ́:t, tlẹ:t,

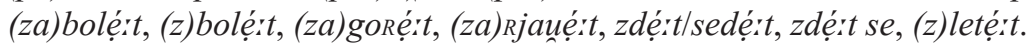

Posebnosti:

1. Nekateri glagoli imajo v 1. os. mn. sedanjika lahko naglas na kračini končnice, npr.: žva'mo/žvér-mo, ta:Rp-'mo/ta:Rpt́'-mo/ta:Rpé:mo.

2. Pripona opisnega deležnika na $-l \mathrm{~m}$. sp. ed. nekaterih glagolov tega tipa se je razvila $\mathrm{v}-o u$ in ne $\mathrm{v}-u$ kot $\mathrm{v}$ sosednjih gorenjskih govorih, npr.: smaR'dou, ta:R'pou.

Tip IB6 - Glagoli na -'ẹ:ti -'em oz. -'ẹ:t -'em, -'ẹ:ti -'nem oz. -'ẹ:t -'nem, -'ẹ:sti -'em oz. 'ẹsst'em 
Glagoli tega tipa imajo akutirano pripono v nedoločniku in kratko naglašeno pripono v ed. sedanjika.

a) glagoli na -ẹ́t -'em:

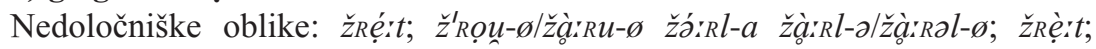
(po)žàar $r t-\varnothing-a$.

Sedanjiške oblike: $\check{z}^{\prime} R e-m \check{z}_{R} e^{\prime}-j o ; \check{z}^{\prime} R-\partial \check{z}^{\prime} \grave{t}^{\prime}-t e$.

Tako še: cvatẹ́t/cvedẹ:t, (na)žrẹ́:t se, (po)žrẹ:t, (po)mRẹ́:t, potprẹ́:t, (Ras)cuetẹ́:t, (u)žrẹ:t se, uprẹ:t se, (u)mrẹe:t, (uo)crẹ:t, uotprẹ:t, zaprẹ́:t, (za)unẹ́:t.

Posebnost: nedovršni glagol mRẹ́:t ima v sedanjiku lahko obliko $m^{\prime}$ Rem ali ma:r'jem.

\section{b) glagoli na -ést -'nem:}

Nedoločniške oblike: napẹ́:t; napẹ:u-ø napẹ́rl-a napẹ:l-ø; napẹ:t; napẹ:t-ø -a.

Sedanjiške oblike: nap'ne-m napné:-jo; nap'n-ə napnì̀-te.

Tako še: pairpẹ́:t, zapẹst, počẹ:t.

Posebnost: glagol začẹ:t je v opisnem deležniku na -lž. sp. ed. cirkumflektiran: začẹ:l-a.

c) Glagoli na -ẹ́rst -'em:

Nedoločniške oblike: snẹ́rst; snẹ:du-ø snẹ́:dl-a -ə; (snẹ:st); (snẹ:den-ø-a).

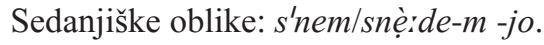

Tip IB7 - Glagoli na -'ẹ:ti -'ẹ:m oz. -'ẹ:t -'ẹ:m

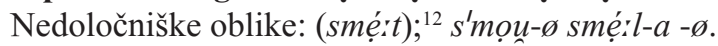

Sedanjiške oblike: smẹ:-m smẹ:-jo.

Tip IB8 - Glagoli na -'ẹtti -'arm oz. -'ẹ:t -'a:m

Nedoločniške oblike: imẹ́:t; i'mou-

Sedanjiške oblike: imàr-m/'mam imàrjo/'majo oz. nt́:ma-m/nt̀:ma-m nú:majo/ nì̀majo; i'ma/imẹ:ìn-ø -te.

Tip ICa1 - Glagoli na -'asti -em oz. -'ast -em

a) akut v nedoločniku, cirkumfleks v sedanjiku:

Nedoločniške oblike: prestást; pRes'tọ-

Sedanjiške oblike: prestà:ne-m -jo; prestá:n-ø -te.

Tako še: uostá:t 'ostati', ustá:t 'vstati'.

Tip ICa2 - Glagoli na -'itti ali -'usti -jem oz. -'it't ali -'ust -jem

a) akut v nedoločniku in sedanjiku:

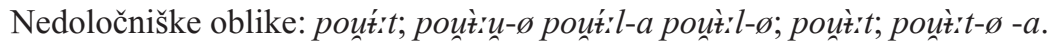

Sedanjiške oblike: poútí:je-m -jo; poùì̀i-ø -te.

Tako še drugi predponski glagoli s to besedotvorno podstavo (ount:t, pa:rutít't,

${ }^{12}$ Nedoločnik glagola smeti se v kroparskem govoru ne uporablja, zato je oblika smẹ́:t tu tvorjena umetno. 


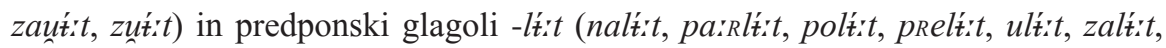
zltít).

Posebnost: glagol pít in predponski glagoli s to besedotvorno podstavo (npr. popt́:t, zapí:t) so v sedanjiku lahko naglašene tudi na priponi: $p j$ je-m pjé:-jo.

\section{b) akut v nedoločniku, cirkumfleks v sedanjiku:}

Nedoločniške oblike: zabt́:t; za'bou-ø/zabt̀'u-

Sedanjiške oblike: zabì̀je-m -jo; zabṫ̀i $i-\varnothing-t e$.

Tako še drugi predponski glagoli z besedotvorno podstavo -bú:t (nabí:t, pobú:t,

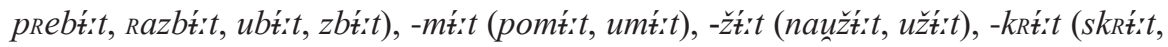

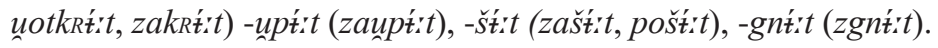

Podobno se spregajo glagoli na -ú:t -jem:

Nedoločniške oblike: obú:t; obù̀u-

Sedanjiške oblike: obù:je-m -jo; obù:in-ø -te.

Tako še drugi predponski glagoli z isto besedotvorno podstavo: (sezú:t, zzú:t) ter podstavo -sú:t (nasú:t, usú:t, zasú:t).

Tip ICa3 - Glagoli na -'ẹti -em oz. -'ẹt -em

a) akut $v$ nedoločniku in sedanjiku:

Nedoločniške oblike: uzẹ́:t; uzẹ̀ru-ø uzẹ́:l-a uzẹ̀:l-ø; uzẹ̀:t; uzẹ̀:t-ø - $a$.

Sedanjiške oblike: uzzá:me-m-jo/unzemér-jo; uzérm-ø/unz'm-ə unzé:m-teluzemì̀-tel uzmìte.

Tako še: objẹ́:t, posnẹ́:t, preuzẹe:t, ujẹ́:t, uarjẹ́t, zajệ:t.

Nedoločniške oblike: žẹ:t; žẹ:u-ø žẹ:l-a žẹell-ø; žẹ:t; (požèè:t-ø-a).

Sedanjiške oblike: žá:ne-m-jo; žá:n-ø -te.

Tako še: mẹ́:t, požẹ́:t, unožẹ:t.

Nedoločniške oblike: predẹ́:t; pred'joun-ø predjà:l-a predjá:l-ø; predẹ:t; predjá:n-ø-a ter zadẹ:t; zadẹ̀:u-ø/za'deu-ø zadẹ́:l-a zadẹ:l-ø; zadẹ:t; zadẹ:t-ø-a.

Sedanjiške oblike: predẹ:n-em predẹ:ne-jo; predé:n-ø predé:n-te ter zadá:ne-m zadá:ne-jo; zadé:n-ø zadé:n-te.

Po obeh vzorcih se lahko sprega tudi glagol udẹ́t.

Nedoločniške oblike: (z)mlẹ́t; (z)m'lou-ø (z)mlẹ́:l-a -ø; (z)mlẹ̀t; (z)zmlẹ̀tt-ø $-a$.

Sedanjiške oblike: (z)mẹ́:le-m -jo; (z)mé:l-ø tel(z)melṫ:tel(z)mlì:te.

Nedoločniške oblike: (za)pẹ́:t; (za)pẹ:u-ø (za)pẹ́:l-a (za)pẹ̀:l-ø; (za)pẹ̀:t; (za)zapẹ:t

Sedanjiške oblike: (za)pó:je-m -jo; (za)pọ̀:i-ø -te.

Nedoločniške oblike: plẹ́t; plệru-ø plệ:l-a plẹ:l-ø; plẹ̀t; (uo)plẹ̀tt-ø -a.

Sedanjiške oblike: plẹ́:ue-m -jo. 
b) akut v nedoločniku, cirkumfleks v sedanjiku (glagoli na -ẹ́:t -ẹ̀:jem):

Nedoločniške oblike: gRẹ́:t; groun-ø gRẹ́:l-a -ø; gRẹ:t; (po)gRẹ:t-ø - $a$.

Sedanjiške oblike: gRẹ:je-m -jo; gRẹ:ìn-ø -te.

Tako še glagol štẹ́:t in predponski glagoli, npr. naštẹ́:t, preštẹ́:t, pogrẹ́st, zgRẹ́t.

Tip ICb1 - Glagoli na -'arsti -em oz. -'arst -em

a) akut v nedoločniku in sedanjiku:

Nedoločniške oblike: párst; pàrsu-ø pársl-a -ə; pàrst; (po)pàršen-ø -a.

Sedanjiške oblike: páise-m -jo; párs-ø -te.

Tako še predponski glagoli, npr. popá:st, ter glagol Rá:st in predponski glagoli (zRásst, preRáist), pri katerih je -t- iz nedoločnika ohranjen tudi v sedanjiku, npr.: Rárstem, zRá:ste.

Nedoločniške oblike: párst; pà:du-ø pá:dl-a -ə; (na)pà:st; (na)pà:den-ø -a.

Sedanjiške oblike: pá:de-m -jo; pá:t-ø -te.

Tako še: prepá:st 'propasti', napá:st, zapopáist 'doumeti'.

b) akut v nedoločniku, cirkumfleks v sedanjiku:

Nedoločniške oblike: (u)kRárst; (u)kRà:du-ø (u)kRá:dl-a-ə; kRàrst; (u)kRà:den-ø $-a$.

Sedanjiške oblike: (u)krà:de-m -jo; (u)krá:t-ø-te.

\section{Tip ICb2 - Glagoli na -'irsti -em oz. -'íst -em}

a) akut v nedoločniku in sedanjiku:

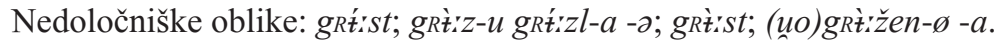

Sedanjiške oblike: gRt́:ze-m -jo; gRt́:s-ø -te.

Tako še predponski glagoli: zgRt́stst, pogRt́:st.

Tip ICb3 - Glagoli na -'ẹrsti ali -'ọrsti -em oz. -'ẹrst ali -'ọst -em

a) akut $v$ nedoločniku in sedanjiku:

Nedoločniške oblike: zé:pst; zé:bl-ə (s. sp.)

Sedanjiške oblike: zé:be-ø (3. os. ed.).

Nedoločniške oblike: górst; gọ:du-ø gọ:dl-a -ə; gọ:st.

Sedanjiške oblike: gọ́:de-m -jo; gọ:t-ø -te.

Tako še predponski glagoli, npr.: zagọ́sst.

b) akut v nedoločniku, cirkumfleks v sedanjiku:

Nedoločniške oblike: usẹ́rst se; usẹ:rdu-ø se usẹ́rdl-a se -a se; usẹ́rst se; (za)sedè:n-ø (za)sedé:n- $a$.

Sedanjiške oblike: usẹ:de-m se -jo se; usẹ́:t-ø se -te se.

Tako še predponski glagoli: sẹ́rst, presẹ́rst se, zasẹ́rst ... 
Nedoločniške oblike: lẹ́:st; lẹ̀:zu-ø lẹ́:zl-a -ə; lẹ:st; (Raz)lẹ̀zzen-ø -a

Sedanjiške oblike: lẹ:ze-m -jo; lẹ́rs-ø-te.

Tako še predponski glagoli: zlẹ́st, pa:Rlẹrst, Razlẹ́rst se.

\section{Tip ICb4 - Glagoli na -'ersti ali -'orsti -em oz. -'erst ali -'orst -em}

a) akut v nedoločniku in sedanjiku:

Nedoločniške oblike: né:st; nẹ́:su-ø nérsl-a -ə; (pre)nesé:n-ø (pre)nesé:n-a.

Sedanjiške oblike: nérse-m -jo/nesér-jo; nérs-ø -te/nest̀̀-te.

Tako še predponski glagoli, npr. pairnérst, prenéist.

Posebnosti:

1. Sem gre verjetno tudi glagol uné:šem/unẹ́š̌em 'najdem po naključju' (1. os. ed. sedanjika), unẹ́:šu (m. sp. ed. opisnega deležnika na -l), ki ga rabijo le v sedanji$\mathrm{ku}$ in opisnem deležniku na $-l .{ }^{13}$

2. Glagoli tega tipa se pri pregibanju različno glasovno premenjujejo: plésst - plé:te-m (tako še splérst, pomérst), prérst - prérde-m (tako še uprérst, gnérst, uobRérst), té:pst - té:pe-m (tako še predponski glagoli, npr. naté:pst, pa:Rtẹ́:pst se, stẹ́:pst se), bórst - bó:de-m (tako še predponski glagoli, npr. zbórst, prebóstst, zabọ́:st), mọ́:ust - mọ́:uze-m (tako še predponski glagoli, npr. pomọ́:ust), dọ́:upst dọ́:ubem/dọ́:lbem/dọ́:lbam (tako še predponski glagoli, npr. zdọ́:upst).

\section{Tip ICc - Glagoli na -či -em oz. -št/-čt -em}

a) akut v nedoločniku in sedanjiku:

Nedoločniške oblike: pé:čt; pẹ́:ku-ø pé:kl-a -ə; pè:čt; pè:čen-ø/pečé:n-ø-a.

Sedanjiške oblike: pé:če-m -jo/pečér-jo; pérc-ø/pérč-ø pércte/pé:čtelpecìttel peč̀tse.

Kot glagol pé:čt še glagol térčt in predponski glagoli iz obeh, npr. pa:Rtérčtt, spérčt.

Posebnosti:

1. Tako se sprega tudi glagol Ré:čt. Če je v velelniku (razen v 2. os. ed.) naglas na priponi, je lahko akutiran ali cirkumflektiran (Rect́tmo/Rect̀̀tmo/Rečṫ'mo).

2. Glagoli, ki v m. sp. ed. opisnega deležnika na $-l$ ne spremenijo kakovosti naglašenega samoglasnika, imajo $\mathrm{v}$ tej obliki cirkumfleks, $\mathrm{v}$ ostalih oblikah opisnega deležnika na $-l$ pa akut, npr. natọ́:učt - natọ̀:uku-ø natọ́:ukl-a natọ́:ukl-ə (tako še:

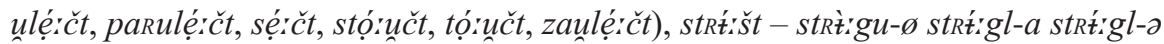
(tako še: dosẹ́šst, postRẹ́:šst, uostét:št).

3. Tudi glagol 'moči' (nedoločnika v kroparskem govoru ne govorijo) ima v sedanjiku in opisnem deležniku na $-l$ akut: $m o \underline{\prime}: R \partial-m$ mọ́:Rə-š/mọ́:R-š $m o o^{\prime} R-j o$ in mọ́:gu-ø mọ́:gl-a mọ́:gla.

\section{b) akut v nedoločniku, cirkumfleks v sedanjiku:}

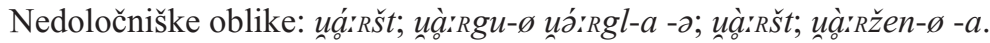

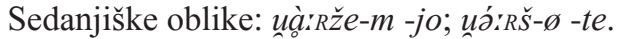

Tako še predponski glagoli z besedotvorno podstavo -lẹ́ršt 'leči', npr.: pa:Rlẹ́:šst

${ }^{13}$ Ta glagol je mogoče slišati le izjemoma in samo še pri starejših Kroparjih. 
se, ulẹeršt selulérčt se, ki imajo v 2. os. ed. velelnika lahko obliko ulẹ́rs-ø namesto ulé:šs-ø/ulẹ:šs-ø.

Tip IČ1 - Glagoli na -ati -'ẹ:m oz. -at -'ẹ:m

Nedoločniške oblike: pouẹ́:dat; pouẹédou-ø pouẹédal-a -ø; pouẹ́:dat; poụ̀:̣:dan-ø -a.

Sedanjiške oblike: poué:-m poue-'jo (2. os. mn. poue-s'te - kot atematski glagol unẹ́:dat); poụ̀:ìi-ø -te.

Tako še predponski glagoli: prepouẹédat, dopouẹ́:dat.

\section{Tip IČ2 - Glagoli na -eti -'ẹ:m oz. -ət -'ẹ:m}

Po tem tipu se pregiba le glagol vedeti, ki pa je atematski glagol (npr. uẹ́:dat uẹ:m).

Tip IIA1 - Glagoli na -ati/-'asti -am 0z. -at/'-at-am/-'arm

Tipa źt:dati/zidásti kot v slovenskem knjižnem jeziku v kroparskem govoru ni, saj se v takih primerih vedno govori kratki nedoločnik, npr. pt́ssat, zí:dat itd. $\mathrm{V}$ to skupino so uvrščeni glagoli, ki se lahko spregajo po tipu IA1 (ko je naglas na glagolski podstavi, npr. štt́xat štt́xxam) ali po tipu IB1 (ko je naglašena pripona, npr. štว'xat štzxà:m). Tako še: štrà̀igat/štrai'gat, mà:ucat se/maúcat se 'goniti se', pomá:ucot/pomaúccat.

\section{Tip IIA2 - Glagoli na -'itti/-iti -'ím oz. -'ot/-(o)t -'itm/-im}

Nedoločniške oblike: stro'jat/stró:init; strojṫ:u-ø/(u)strọ́:ju-ø strojt̄:l-a -ø/ (u)strọ́:jal-ø; stró:int/stro'jat; (u)strọ̀ijen-ø -al(u)stroljen-ø (u)strojé:n-a.

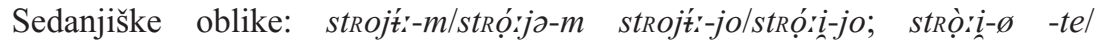
strojt̀:-te.

Ko je naglas na glagolski podstavi (stRó:int strọ́:jo-m), se glagol pregiba po spregatvenem vzorcu tipa IA4, če pa je naglašena pripona, se pregiba po spregatvenem vzorcu tipa IB4 (stro'jat strojẗ́'-m).

Tip IIB1 - Glagoli na -'arti -em oz. -'art/-'at -em

a) kratki naglašeni samoglasnik ali akut v nedoločniku, akut v sedanjiku:

Nedoločniške oblike: is'kat; t́'skou-ø/is'kou-ø iskà:l-a iská:l-ø; is'kat/t'tskat; iská:n-ø-a.

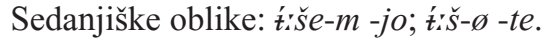

Tako še: (z)la'gat, (po)klá:t, postlá:t, (u)gná:t, uobis'kat, (za)gná:t, (za)klá:t, (z) gná:t.

Posebnosti:

1. Glagol $d$ jatot/djá:t ima sedanjik dẹ:ne- $m$ in velelnik dẹ́:n-ø.

2. Nekateri glagoli imajo v velelniku, opisnem deležniku na $-l$ in namenilniku drugačen tonemski naglas, kot je v glavnem spregatvenem vzorcu:

Nedoločniške oblike: kouárt (tudi potko'uat); kouàrun-ø kouá:l-a kouàrl-ø; kouà:t/ko'uat; kouáan-ø -a.

Sedanjiške oblike: kú:je-m kú:je-jo; kùrin-ø kùri-te.

Tako še predponski glagoli poko'uat, skouná:t, unkouáat; glagol brá:t in pred- 
ponski glagoli, npr. nabRá:t, pobRá:t, prebrá:t, unobRá:t, zbRá:t; glagol prá:t in predponski glagoli úoprá:t; glagol uo'Rat in predponski glagoli zo'Rat; in še nekaj drugih glagolov: je'mat, poslá:t. Zdi se, da so v tem tipu glagolov pogostejši oz. običajnejši dolgi nedoločniki.

\section{b) kratki naglašeni samoglasnik ali akut v nedoločniku, cirkumfleks v se- danjiku:}

Nedoločniške oblike: s'jat/sjá:t; sjà:u-ø sjà:l-a -ø; sjàrt; (po)sjá:n-ø-a.

Sedanjiške oblike: sẹ̀:je-m -jo; sệri-ø -te.

Tako še predponski glagoli: pos'jat, pRes'jat.

$\mathrm{V}$ ta tip gredo tudi vsi glagoli s pripono -o'vati -'u:jem oz. -'uat -'u:jem:

Nedoločniške oblike: kəp'uat; kәp'uou-ø kəpuà:l-a kəpuá:l-ø; kəp'uat; kəpuá:n-ø-a.

Sedanjiške oblike: kəpùi:je-m -jo; kəpù̀i

Tako še: boux'uat 'trebiti bolhe', del'vat/delvá:t, dopoued'uat, gost'vat, imen'uat, issel'uat, naroč'uat, pa:rpoud'uat, pot'uat, potreb'uat, pouel'uat, poxaik'uat, premišsal'uat, Raskaz'vat, Razlik'uat, sklic'vat selsklicvárt se, spoud'uat, spak'uat, spraš'uat, stan'vat, ubdaR'uat, zasled'vat. Tu so običajnejši kratki nedoločniki (dolgi so izjemni).

\section{Tip IIB2 - Glagoli na -'itti -im oz. -'ot -om}

a) akutiran sedanjik:

Nedoločniške oblike: sellat; sé:lu-ø/selt̀'u-ø selt̀:l-a selt:ll-ø; se'lat; (pre)sellen-ø/(pre)sẹ́:len-ø (pre)selé:n-al(pre)sẹ́:len-a.

Sedanjiške oblike: sẹ́:la-m sẹ́:l-jo; sé:l-ø-te.

\section{b) cirkumflektiran sedanjik:}

Nedoločniške oblike: (po)pepelat se; (po)pepẹ́:lu-ø se (po)pepelt̀:l-a se (po)pepelí:l-ø sel(po)pepẹ́:lla se; (po)pepe'lat se; (po)pepelé:n-ø -a.

Sedanjiške oblike: (po)pepẹ:llo-m se -jo se; (po)pepẹ́:l-ø se -te se.

Tip IIB3 - Glagoli na -'ẹti -em oz. -'ẹ:t -em

\section{a) akut v nedoločniku in sedanjiku:}

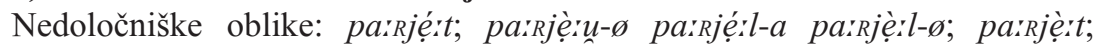
(s)pa:Rjẹ:t-ø - $a$.

Sedanjiške oblike: pré:me-m -jo; pRt́:m-ø -te.

Tako še predponski glagoli, npr. spa:Rjẹ:t.

Nedoločniške oblike: sprejẹ́:t; sprejẹ:u-ø sprejệ:l-a sprejẹ̀l-ø; sprejẹ:t; sprejẹ̀t $\varnothing-a$.

Sedanjiške oblike: sprẹ́:inme-m -jo; sprẹ́:jm-ə sprejmì̀-te.

Nedoločniške oblike: (xotẹ́:t); ${ }^{14} u$ ó:tu-ø úó:tl-a -ə.

${ }^{14}$ Nedoločnik glagola hoteti se $\mathrm{v}$ kroparskem govoru ne uporablja, zato je oblika xotẹ́:t tu tvorjena umetno. 


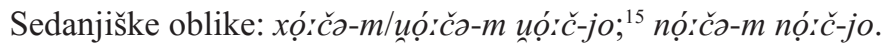

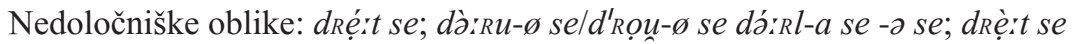

Sedanjiške oblike: dé:Re-m se -jo selderé:jo se; dé:R-ø seldert̀̀-te seldrì̀-te se.

Nedoločniške oblike: klẹ́:t; klẹ:u-ø klẹ́:l-a klẹ:l-ø; klẹ:t; (pre)klẹ:t-ø -a.

Sedanjiške oblike: kó:une-m -jo; kọ́:un-ə kọ́:uən-te.

\section{Tip IIB4 - Glagoli na -ati -'ím oz. -at -'tim}

Nedoločniške oblike: dár:Ržat; dá:Ržou-ø da:Ržà:l-a da:Ržá:l-ø; dá:Ržat; (za)da:Ržá:n-ø -a/(za)dà:Ržan-ø-a.

Sedanjiške oblike: dar:Ržťt'-m jo/da:Rž-ẹ́:/da:Rž-é:jo; dá:RŠ-ø -te.

Tako še: bré:nčat, cvág:Rčat (nima velelnika), klẹ́čat, lé:žat, mớ:učat, tt́:šat, (za)mí:žat (gre za glagole s kratkim nedoločnikom, pri katerih je v knjižnem jeziku mogoč le dolgi nedoločnik).

Posebnosti:

1. Ti glagoli imajo poleg naglašene pripone $-t^{\prime}-\mathrm{v}$ needninskih oblikah tudi pripono -é-, npr. da:Ržé:jo, klečé:jo.

2. V tem tipu glagolov je pogosta kratka oblika za 3. os. mn. sedanjika z naglašeno končnico éé, npr. da:Ržéér, mižér.

3. Glagol bé:žat bežt́m ima velelnik bẹ̀riš-ø bẹ̀riš-te.

4. Glagol zalú:čat zalčt́m je v opisnem deležniku na $-l$ ed. m. sp. cirkumflektiran: zalù:ču (toda zalú:člo - m. sp. mn.).

\section{Tip IIB5 - Glagoli na -iti -'ím oz. -(o)t -'tím}

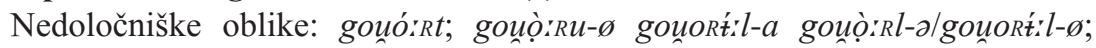
gouó:Rt; (z)gouorjé:n-ø - $a$.

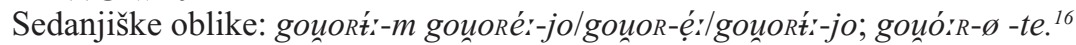

Tako še predponski glagoli: pogouó:Rt se, zgouó:Rt se.

Posebnosti:

1. Ti glagoli imajo poleg naglašene pripone $-t_{i}^{\prime}-\mathrm{v}$ needninskih oblikah tudi pripono -é-, npr. gouoré:jo.

2. Govori se tudi kratka oblika za 3. os. mn. sedanjika z naglašeno končnico -ér, npr. zgouor-ẹ́r se.

\section{Tip IIB6 - Glagoli na -'ust -em}

Nedoločniške oblike: mnú:t; mnù̀u-

Sedanjiške oblike: mí:ne-m -jo.

Tako še predponski glagoli: premnút.

\footnotetext{
${ }^{15}$ Posebna (tj. od drugih glagolov tega tipa razlikujoča se) je tudi oblika za 2. os. ed.: ù̀̇̌̌ $\varnothing$ luọ́:čə-š oz. nò:čø nọ́:čə-šs, kjer je kratka oblika cirkumflektirana, dolga pa akutirana.

${ }^{16}$ Prednaglasni /o/ tega glagola je lahko oslabljen v polglasnik (gouərét:̌̆) ali /a/ (gouanét:m, gouartí).
} 


\section{Sklep}

Sinhroni pregled oblikospreminjevalnih vzorcev glagolov v krajevnem govoru Krope na Gorenjskem je bil zasnovan na način, ki se je v zadnjih letih uveljavil v slovenski dialektologiji na podlagi Riglerjeve tipologije glagolskih oblik slovenskega knjižnega jezika, predstavljene v uvodu Slovarja slovenskega knjižnega jezika (podobne opise najdemo npr. v Smole 1996, Weiss 1998, Jakop 2003). Ta tipologija temelji ne le na različnih glagolskih priponah, ampak predvsem na naglasnem mestu v nedoločniku in sedanjiku. V članku so poleg teh dveh predstavljene tudi nekatere oblike velelnika, opisnega deležnika na $-l$, namenilnika in deležnika na - $n$ oz. - $t$.

Primerjava kroparskega krajevnega govora s slovenskim knjižnim jezikom kaže nekaj izrazito narečnih potez. Zanj je npr. značilno, da se pri glagolih z nepremičnim naglasom na osnovi (glede na nedoločnik in sedanjik) rabi samo kratki nedoločnik, in sicer tudi tam, kjer je v knjižnem jeziku mogoč tudi dolgi nedoločnik, tako npr. v akutiranih glagolih na -at -am (tip IA1, zt́:dat), v glagolih na -at -em (tip IA3, smẹ́:jat se in kolẹ̀rdvat), ki v nedoločniku in sedanjiku ne spreminjajo tonema, ter glagolih tipa IIB4 (dá':Ržat) in IIB5 (gouó:Rt), ki imajo v nedoločniku naglas na osnovi, v sedanjiku pa na priponi (v knjižnem jeziku obakrat le na priponi). Tudi glagoli tipov IB1 (ig'Rat), IB4 (lo'ust), IIA1 (šta'xat), IIA2 (stro'jat), IIB1 (is'kat, $\left.s^{\prime} j_{g} t, k \partial p^{\prime} u \partial t\right)$ in IIB2 (se'lat, pepe'lat) imajo naglas na kratkem (redko dolgem) samoglasniku pripone.

Glagoli z naglašeno sedanjiško pripono -t́:m imajo v množinski in dvojinski obliki pogosto dvojnično pripono -é:- (npr. IB2 spt́:jo in spé:jo, IB4 louté:jo in louérjo, IB5 žutútjo in žué:jo, IIB4 darRžt́íjo in da:Ržé:jo, IIB5 gouort́:jo in gouoré:jo). Ti glagoli imajo v 3. osebi množine lahko tudi kratko obliko z naglašeno končnico -ẹ́: (žués). Pri akutiranih glagolih tipa ICa3 (uzẹ́:t), ICb4 (nésts) in (pé:čt) je v sedanjiku mogoča dvojnica glede mesta naglasa, in sicer je naglas lahko na osnovi ali na priponi (uzá:mejo ali unzemé:jo, né:sejo ali nesérjo, pé:čejo ali pečé:jo).

Dvojnice glede mesta naglasa in njegovega tonema imajo nekateri tipi glagolov tudi v množini in dvojini velelnika, npr. tip IB4 lo'uat/loutít (lọ́:ute in loụ'te

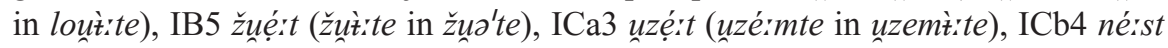
(nérste in nesìte).

Predstavljeno je tudi spreminjanje tonema $\mathrm{v}$ različnih oblikah opisnega deležnika na $-l$. Tu naj bo zato le še opozorjeno na naglasne dvojnice v nekaterih tipih glagolov, npr. v tipu IA1 (zt́́:dat), IA5 (potẹ́:gant), IB5 (žuẹét), IB6 (žnẹ́:t), IIB1 (is'kgt), IIB2 (se'lat) in IIB6 (gouó:'Rt), kjer je naglas mogoč tako na osnovi kot

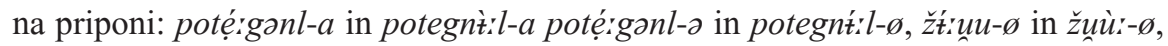

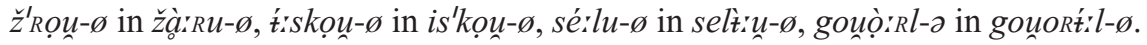

Kot $\mathrm{v}$ drugih obravnavanih oblikah je tudi $\mathrm{v}$ deležniku na $-n$ oz. $-t$ mogoče ugotoviti nekaj naglasnih posebnosti, tako npr. dvojnic v tipih ICb4 (prebóstst) in ICc (pé:čt t) ter IIB2 (se'lat) in IIB4 (zadá:Ržat): (pRe)bodé:n-ø in (pre)bọ̀:den-ø ter (pre)bodé:n- $a$ in (pre)bọ̀dden-a, pè:čen-ø in pečé:n- $\varnothing,(p R e) s e$ len-ø in (pre)sẹ́:len-ø ter (pre)selé:n- $a$ in (pre)sẹ́:len- $a$, (za)da:Ržá:n-ø- $a$ in (za)dà:Ržan-ø-a. 


\section{Literatura}

Jakop, Tjaša, Tipologija narečnih glagolskih oblik na primeru govora Ložnice pri Žalcu, Slavistična revija 51, 2003, št. 1, 1-25.

Rigler, Jakob, Premene tonemov v oblikoslovnih vzorcih slovenskega knjižnega jezika, Jezik in slovstvo 11, 1966, št. 1/2, str. 24-35.

Rigler, Jakob, Akcentske variante I, Slavistična revija 18, Ljubljana, 1970, št. 1-2, 5-15 (O naglasu v opisnem deležniku na -l).

Rigler, Jakob, Akcentske variante III, Slavistična revija 26, Ljubljana, 1978, št. 4, 365-374 (O naglasu v nedoločniku).

Slovar slovenskega knjižnega jezika I, A-H, Ljubljana, SAZU, Inštitut za slovenski jezik, DZS, 1980, LV-LVIII.

Smole, Vera, Oblikoglasje in oblikoslovje šentruperskega govora. Doktorsko delo. Ljubljana, 1994, 11-27, 59-87, 245-247.

Smole, Vera, Tonemski naglas glagolskih oblik v šentrupertskem govoru, Razprave SAZU, Dissertationes XV, Ljubljana, SAZU, Razred za filološke in literarne vede, 1996, 269-288.

Šekli, Matej, Tonemski naglasni tipi glagola v (knjižni) slovenščini, Jezikoslovni zapiski 11/2, Ljubljana 2005, 31-61.

Škofic, Jožica, Glasoslovje, oblikoslovje in besedišče govora Krope na Gorenjskem. - Doktorska disertacija. Ljubljana, 1996, 194-237.

Škofic, Jožica, Onemitev in oslabitev samoglasnikov v kroparskem govoru, Slavistična revija 44, Ljubljana 1996, št. 4, 471-479.

Škofic, Jožica, Fonološki opis govora Krope (SLA 202), Jezikoslovni zapiski 3, Ljubljana 1997, 175-189.

Škofic, Jožica, Nekatere glasoslovne značilnosti govora Krope na Gorenjskem, Logarjev zbornik, Zora 8, Maribor 1999, Slavistično društvo, 99-108.

Škofic, Jožica, Govorica jih izdaja: skica govora kovaške Krope, Kropa, Tomco, 2001.

Toporišič, Jože, Glagolski oblikotvorni naglas moščanskega govora, Razprave SAZU, Dissertationes XIII, Ljubljana, SAZU, Razred za filološke in literarne vede, 1990, 99-107.

Toporišič, Jože, Slovenska slovnica, Maribor 1976, Založba Obzorja, 282-342.

Weiss, Peter, Slovar govorov Zadrečke doline, Poskusni zvezek A-H, Ljubljana, Založba ZRC, 1998, 51-58.

\section{Verbal Word-Formation Patterns in the Upper Carniolan Sub-Dialect of Kropa}

\section{Summary}

This synchronic overview of verbal word-formation patterns in the local sub-dialect of Kropa in Upper Carniola follows Rigler's typology of verb forms in standard Slovenian in the introduction to the Standard Slovenian Dictionary. This 
typology is based on various verbal suffixes and stress positions in the infinitive and present tense. In addition to these two forms, this article also presents certain forms of the imperative, the 1-participle, the supine, and the n/t-participle.

A comparison of the local sub-dialect of Kropa with standard Slovenian reveals some clear dialect features: verbs with immobile stress on the stem (with regard to the infinitive and present tense) have only a short infinitive where the standard language can also have a long infinitive; for example, for verbs with an acute accent in -at -am (type IA1, zí:dat), for verbs in -at -em (type IA3, smẹ́:jat se and kolẹ̀:dvat), which do not change their toneme in the infinitive and the present tense, and for type IIB4 verbs (dǻ:Ržat) and type IIB5 verbs (gouó:Rt), which have stress on the stem in the infinitive but on the suffix in the present tense (in standard Slovenian both have stress only on the suffix). Verbs of the types IBI (ig'Rət), IB4 (lo'ůt), IIA1 (šta'xət), IIA2 (stro'jat), IIB1 (is'kət, s'jatot, kəp'uِt), and IIB2 (se'lat, pepe'lat) also have a short (rarely long) stressed vowel in the suffix.

Verbs with the stressed present-tense suffix -1:m often have the alternative suffix -é:- in plural and dual forms (e.g., IB2 spí:jo and spé:jo, IB4 louí:jo and loué:jo, IB5 žứí:jo and žué:jo, IIB4 dạ:Rží:jo and då:Ržé:jo, IIB5 gounoní:jo and gounoré:jo). In the third-person plural these verbs can also have a short form with the stressed ending -ẹ́: (žué:). For verbs with an acute accent of the types ICa3 (ưzẹ́:t), ICb4 (né:st), and (pé:čt), there are possible doublets in the present tense with regard to stress position; the stress may be on the stem or on the suffix (uzá:mejo or unzemé:jo, né:sejo or nesé:jo, pé:čejo or pečé:jo).

Certain types of verbs also have doublets with regard to the stress position and its toneme in the plural and dual forms of the imperative; for example, types

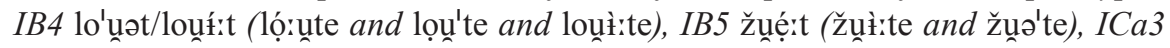
unzẹ́:t (ưzé:mte and unzemì̀te), and ICb4 né:st (né:ste and nesì̀te).

Variation of the toneme in various forms of the 1-participle is also presented. Here attention should also be drawn to stress doublets in certain verb types; for example, in types IA1 (zí:dat), IA5 (potẹ́:gənt), IB5 (žuẹét), IB6 (Žrẹe:t), IIBI (is'kạt), IIB2 (se'lat), and IIB6 (gouó: Rt), in which the stress can appear on both the stem and the suffix: potẹ́:gənl-a and potegnì:l-a potẹ́:gənl-ə and potegní:l-ø, žź:uuu- $\varnothing$ and

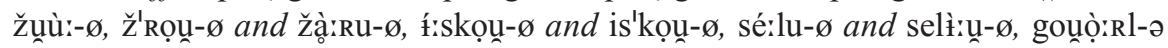
and gounoríll-ø.

Like the other forms discussed, the n/t-participle also has certain special stress features; for example, doublets in types ICb4 (prebó:st) and ICc (pé:čt); as well as IIB2 (se'lət) and IIB4 (zadắ:Ř̌at): (pre)bodé:n- $\varnothing$ and (pre)bọ̀:den-ø as well as (pre)bodé:n-a and (pre)bọ̀:den-a, pè:čen-ø and pečé:n-ø, (pre)se'len-ø and (pre)sẹ́:len-ø, as well as (pre)selé:n-a and (pre)sẹ́:len-a, (za)da:Ržá:n-ø -a and (za)dà:Ržan-ø -a.

Priloga: Pregled tipov glagolov v kroparskem govoru, kot ga izkazuje zbrano narečno gradivo 

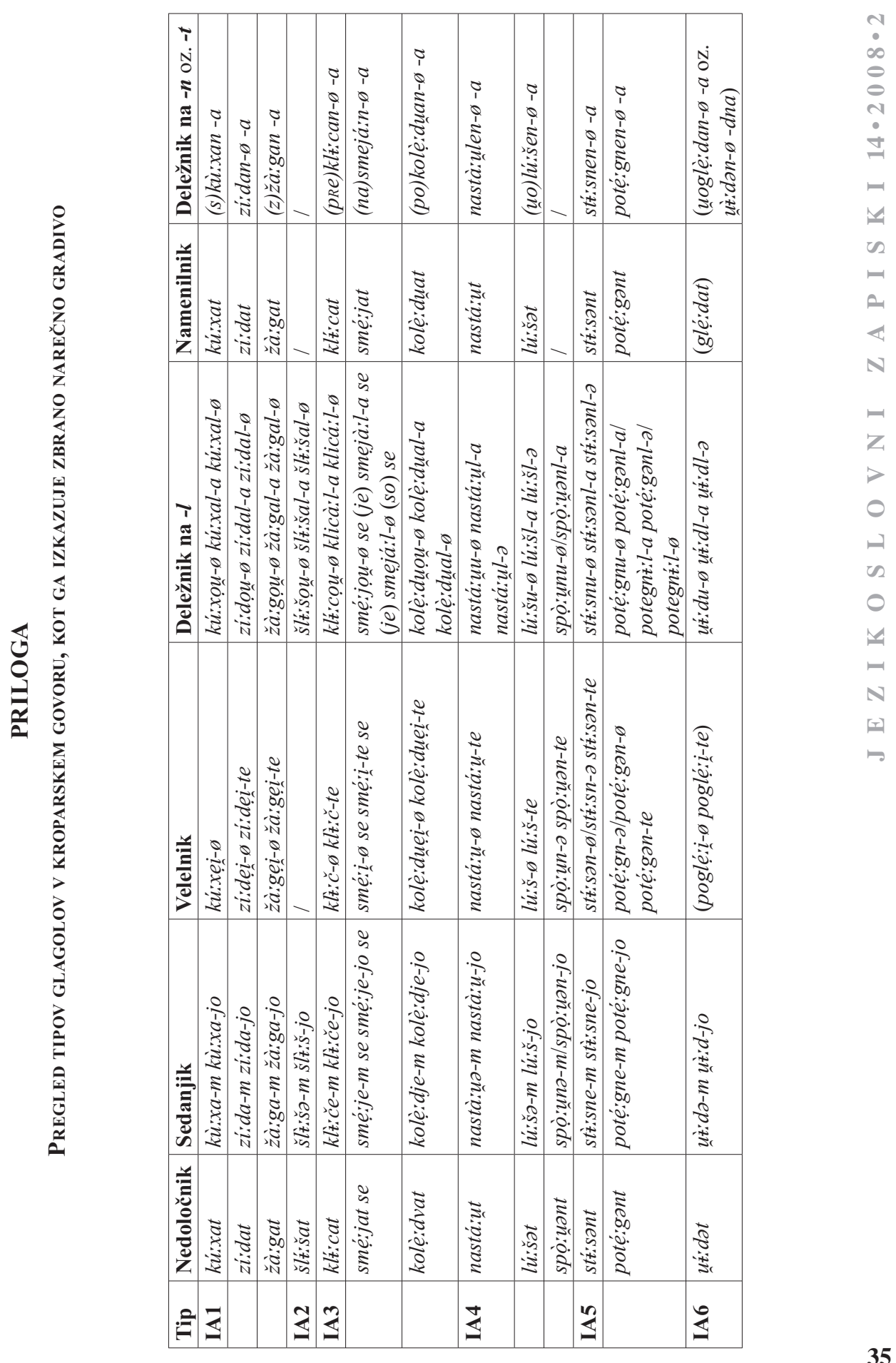


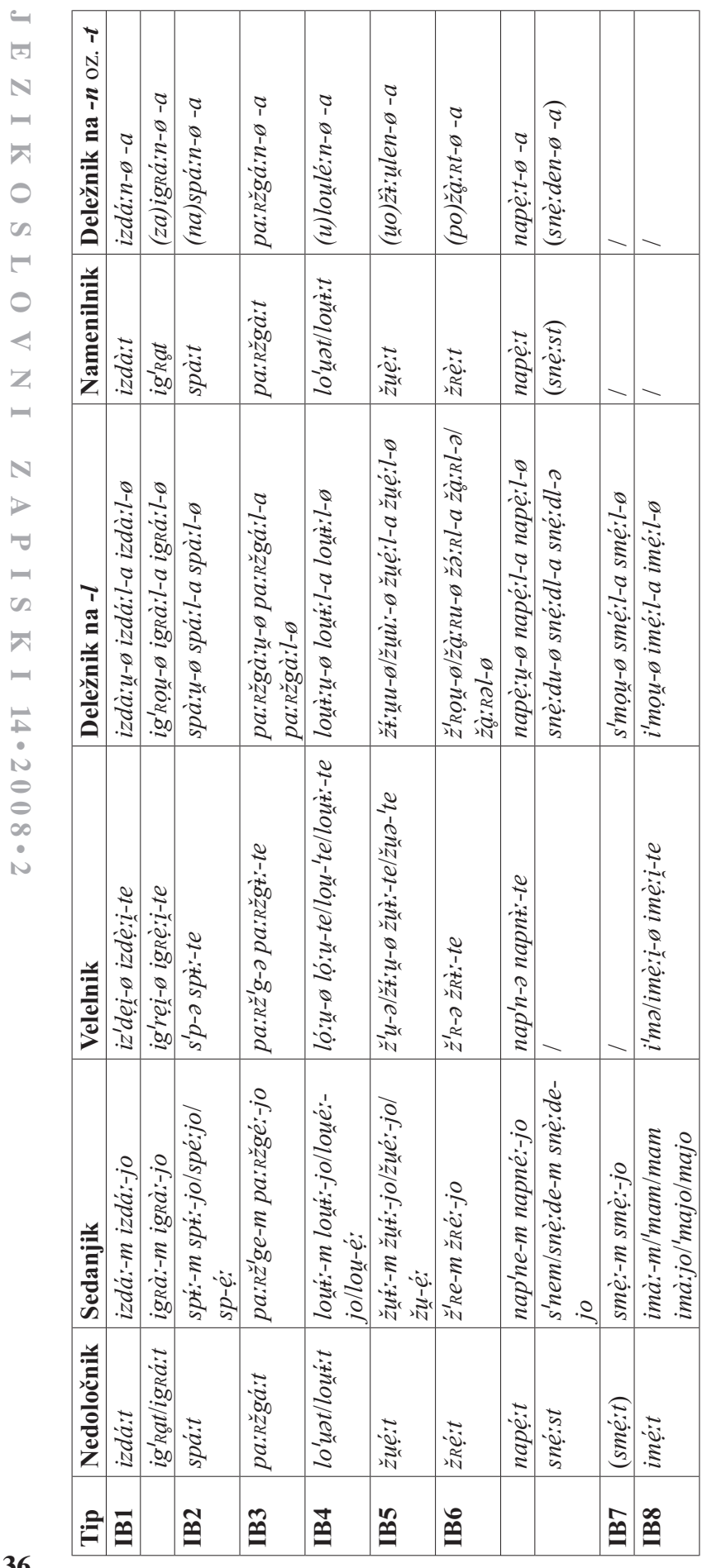




\begin{tabular}{|c|c|c|c|c|c|c|c|c|c|c|c|c|c|c|c|c|c|c|c|}
\hline 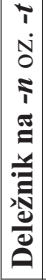 & - & $\begin{array}{c}0 \\
1 \\
0 \\
1 \\
-1 \\
0 \\
0 \\
0 \\
0\end{array}$ & 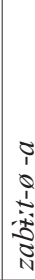 & 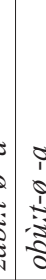 & 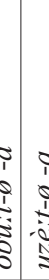 & 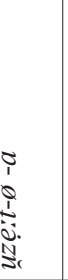 & $\begin{array}{c}0 \\
1 \\
0 \\
1 \\
0.0 \\
0 \\
0 \\
0 \\
0 \\
0\end{array}$ & $\begin{array}{c}0 \\
1 \\
0 \\
1 \\
5 \\
2 \\
\vdots \\
0 \\
0 \\
2 \\
3\end{array}$ & 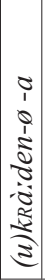 & 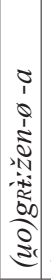 & & - & 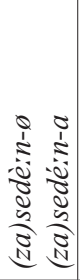 & 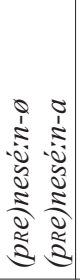 & 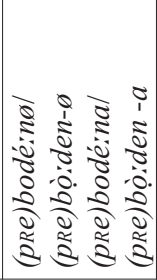 & 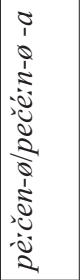 & 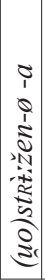 & 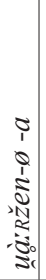 & 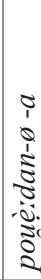 \\
\hline 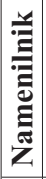 & - & 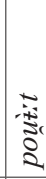 & 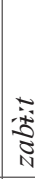 & 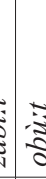 & 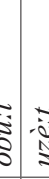 & 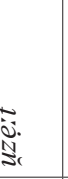 & 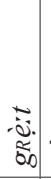 & $\begin{array}{l}\tilde{y} \\
\vdots \\
\vdots \\
\vdots \\
2\end{array}$ & 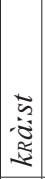 & 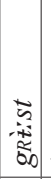 & & $\left|\begin{array}{l}\tilde{n} \\
\vdots \\
0 \\
0 \\
0 \\
0\end{array}\right|$ & $\begin{array}{c}0 \\
\vdots \\
\vdots \\
\vdots \\
\vdots \\
\vdots \\
\vdots \\
0\end{array}$ & - & $\begin{array}{l}\tilde{y} \\
0 \\
0 \\
8\end{array}$ & 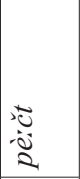 & 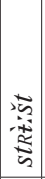 & 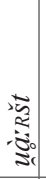 & \\
\hline 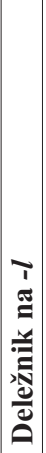 & 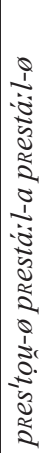 & 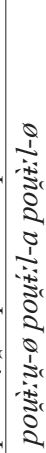 & 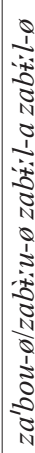 & 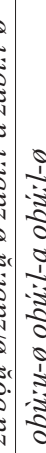 & 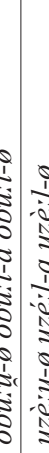 & 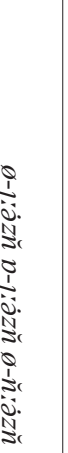 & 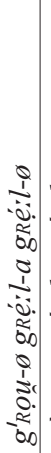 & $\begin{array}{c}0 \\
1 \\
\vdots \\
0 \\
0 \\
0 \\
1 \\
\vdots \\
0 \\
0 \\
0 \\
0 \\
1 \\
0 \\
0 \\
0 \\
0\end{array}$ & 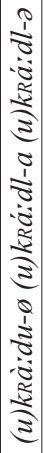 & 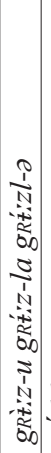 & 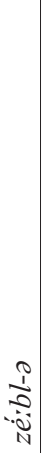 & 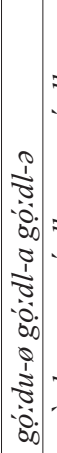 & 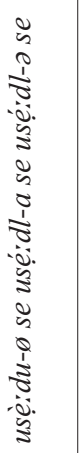 & 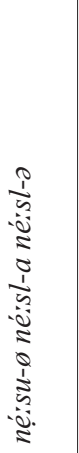 & 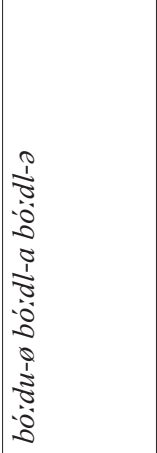 & 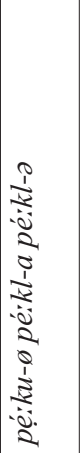 & 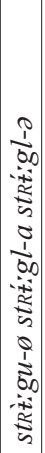 & 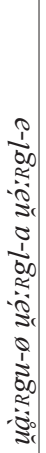 & $\frac{1}{3}$ \\
\hline$\frac{y}{\frac{3}{3}}$ & 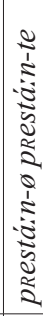 & 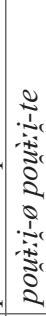 & 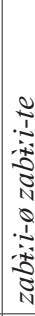 & 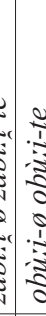 & 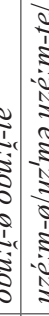 & 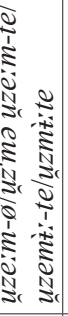 & 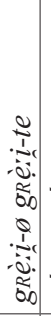 & $\begin{array}{c}0 \\
0 \\
1 \\
0 \\
0 \\
0 \\
0 \\
\vdots \\
0 \\
0 \\
2\end{array}$ & 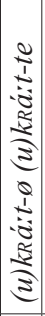 & 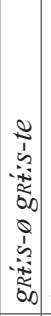 & & 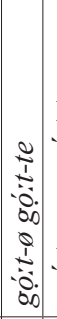 & 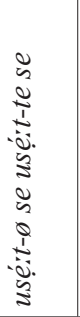 & 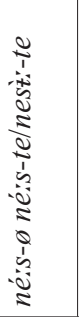 & $\begin{array}{l}0 \\
1 \\
\vdots \\
0 \\
0 \\
0 \\
1 \\
0 \\
0 \\
0\end{array}$ & 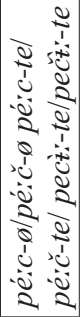 & 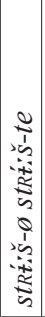 & 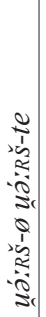 & 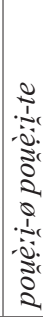 \\
\hline 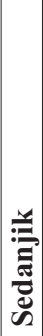 & 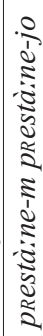 & 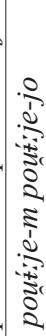 & 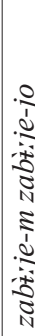 & 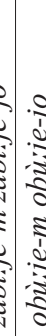 & 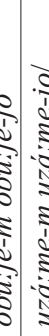 & 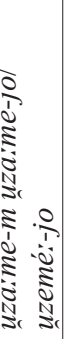 & 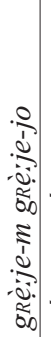 & 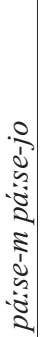 & 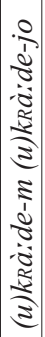 & 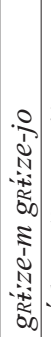 & 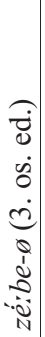 & 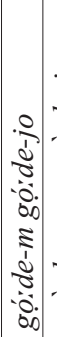 & 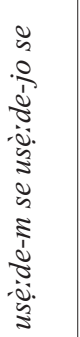 & 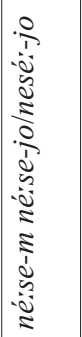 & 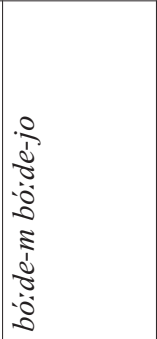 & 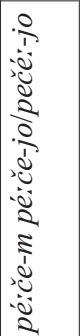 & 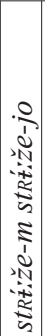 & 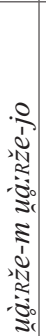 & 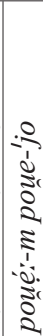 \\
\hline 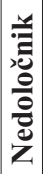 & 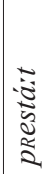 & 薏 & స్ & 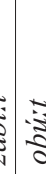 & 5 & N & . & $\begin{array}{l}\tilde{a} \\
\vdots \\
\vdots \\
\vdots\end{array}$ & $\frac{\pi}{3}$ & $\mid$ & 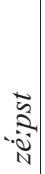 & 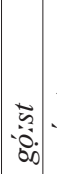 & 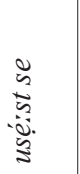 & 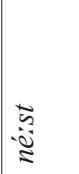 & $\begin{array}{l}\tilde{y} \\
\tilde{0} \\
0\end{array}$ & 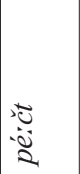 & 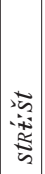 & 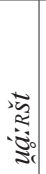 & 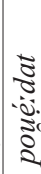 \\
\hline 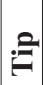 & & $\mathcal{U}$ & & & & $\underline{5}$ & & $\overline{0}$ & & $\underline{\tilde{U}}$ & & & & 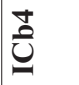 & & 니 & & & \\
\hline
\end{tabular}




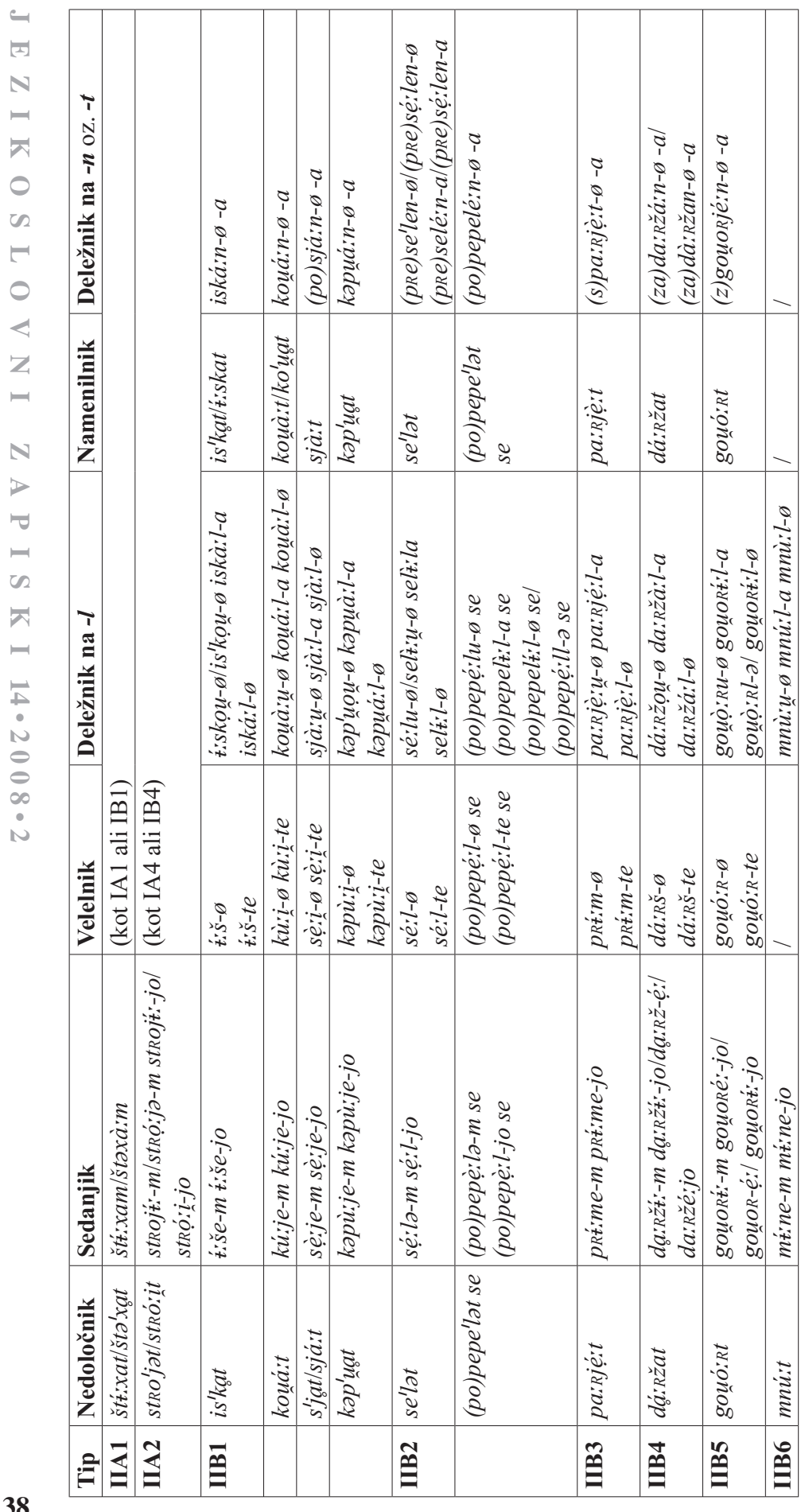

